\title{
SYNGAP1: Mind the Gap
}

\author{
Nallathambi Jeyabalan ${ }^{1}$ and James P. Clement ${ }^{2 *}$ \\ ${ }^{1}$ Narayana Nethralaya Post-Graduate Institute of Ophthalmology, Narayana Nethralaya Foundation, Narayana Health City, \\ Bangalore, India, ${ }^{2}$ Neuroscience Unit, Jawaharlal Nehru Centre for Advanced Scientific Research, Bangalore, India
}

A cardinal feature of early stages of human brain development centers on the sensory, cognitive, and emotional experiences that shape neuronal-circuit formation and refinement. Consequently, alterations in these processes account for many psychiatric and neurodevelopmental disorders. Neurodevelopment disorders affect $3-4 \%$ of the world population. The impact of these disorders presents a major challenge to clinicians, geneticists, and neuroscientists. Mutations that cause neurodevelopmental disorders are commonly found in genes encoding proteins that regulate synaptic function. Investigation of the underlying mechanisms using gain or loss of function approaches has revealed alterations in dendritic spine structure, function, and plasticity, consequently modulating the neuronal circuit formation and thereby raising the possibility of neurodevelopmental disorders resulting from synaptopathies. One such gene, SYNGAP1 (Synaptic Ras-GTPase-activating protein) has been shown to cause Intellectual Disability (ID) with comorbid Autism Spectrum Disorder (ASD) and epilepsy in children. SYNGAP1 is a negative regulator of Ras, Rap and of AMPA receptor trafficking to the postsynaptic membrane, thereby regulating not only synaptic plasticity, but also neuronal homeostasis. Recent studies on the neurophysiology of SYNGAP1, using Syngap 1 mouse models, have provided deeper insights into how downstream signaling proteins and synaptic plasticity are regulated by SYNGAP1. This knowledge has led to

OPEN ACCESS

Edited by: Milos Petrovic University of Belgrade, Serbia

Reviewed by: Sathyanarayanan Puthanveettil, The Scripps Research Institute, USA Nathalie Sans, University of Bordeaux, France

${ }^{*}$ Correspondence: James P. Clement chelliah@jncasr.ac.in

Received: 19 May 2015 Accepted: 29 January 2016 Published: 15 February 2016

Citation: Jeyabalan N and Clement JP (2016) SYNGAP1: Mind the GAP.

Front. Cell. Neurosci. 10:32. doi: 10.3389/fncel.2016.00032 a better understanding of the function of SYNGAP1 and suggests a potential target during critical period of development when the brain is more susceptible to therapeutic intervention.

Keywords: SYNGAP, synaptic plasticity, intellectual disability, autism spectrum disorders, learning and memory, neurodevelopmental disorders

\section{INTRODUCTION}

The brain is the center of the nervous system and is the most complex organ in the body. All day-to-day activities including executive decisions, memories, emotions, and cognitive tasks are mediated by the cerebral activity. Apart from coordinating the ability to smell, touch, hear, taste, and see, the brain enables people to form words, perform mathematical calculations, communicate using different languages, grasp and appreciate music, make decisions, organize and plan everyday activities and above all, imagine. Therefore, normal development of brain is imperative for performing these and other essential functions. A cardinal feature of early stages of human brain development centers on the sensory, cognitive, and emotional experiences that shape neuronal-circuit formation and refinement. Consequently, alteration in any of these features accounts for many psychiatric and neurological disorders (Spooren et al., 2012; Kroon et al., 2013). 
The human brain consists of 86 billion neurons and 85 billion non-neuronal cells (Azevedo et al., 2009), which play a vital role in information processing and transmission in the form of electrical signals through specialized junctions called synapses. Neuroscientists have made great progress in unraveling the cellular and molecular mechanisms of dendritic spine synapse formation and function, which is considered as one of the most remarkable developments in biology in the last three decades. A precise control of synaptic development and neuronal connectivity has been found to be necessary for normal brain development. Conversely, abnormal dendritic spine morphology and function can lead to disruption of neuronal circuits, and consequently can result in various psychiatric and neurodevelopmental disorders (NDDs; Melom and Littleton, 2011).

Altered dendritic spine function and neuronal circuit formation account for one of the major underlying mechanisms of Intellectual Disability (ID) and Autism Spectrum Disorder (ASD; Chechlacz and Gleeson, 2003; Kroon et al., 2013), which are often co-diagnosed in young children with NDDs and affect $1-3 \%$ of the general population. Due to high rates of comorbidity of these NDDs, it has been broadly hypothesized that ID and ASD share common neurodevelopmental pathologies that lead to various behavioral and cognitive symptoms that define these disorders. The underlying cause of these NDDs are believed to be mutations in genes, parental drug use and aging process, viral infections and other environmental factors (van Spronsen and Hoogenraad, 2010).

Recent evidences from many animal models of ID and ASD suggest that mutations that cause NDDs occur in genes encoding the proteins that regulate synaptic function and/or structure (Boda et al., 2002; Bear et al., 2004; Ramocki and Zoghbi, 2008; Südhof, 2008; Gauthier et al., 2011; Penzes et al., 2011). Mutations in many of these single-genes are the major cause of syndromic and non-syndromic ID (NSID; Bhakar et al., 2012; Zoghbi and Bear, 2012). The most common singlegene mutations in ASD with ID are associated with Fragile $\mathrm{X}$ syndrome (FXS; FMRI), Tuberous Sclerosis (TSC1, TSC2), Angelman Syndrome (UBE3A), Rett Syndrome (MECP2), and Phlean-McDermid syndrome (SHANK3). Rare mutations in single-genes, such as those encoding for Neuroligin (NLGN3, NLGN2) and Neurexin (NRXN1), are also implicated in ID and ASD. These genes are just a few of many implicated in NDDs, suggesting that highly penetrant mutations of genes play an important role in regulating synaptic function. Heterozygous mutation in SYNGAP1 cause ID and ASD, and whose product is now established as a major regulator of synaptic function.

Numerous studies have shown that a major share of dendritic spine synapses utilize the excitatory neurotransmitter, glutamate, to activate $\mathrm{N}$-methyl $\mathrm{D}$-aspartate receptors (NMDARs), which are associated with a vast array of transmembrane proteins, scaffolding proteins and many signaling proteins (Pèrez-Otaño and Ehlers, 2004; Lau and Zukin, 2007; Kerchner and Nicoll, 2008; Lai and Ip, 2013; Fan et al., 2014). SYNGAP1, is a downstream component of NMDAR-associated signaling complex that negatively regulates activation of small GTP-ase
(Ras- and Rap-GAP) and of $\alpha$-amino-3-hydroxy-5-methyl4-isoxazolepropionic acid receptor (AMPAR) trafficking to excitatory postsynaptic membrane (Rumbaugh et al., 2006; Huang, 2009; Walkup et al., 2015). SYNGAP1 is a $\sim 140 \mathrm{kDa}$ protein located on Chromosome 6p21.3 (Figure 1; Husi et al., 2000). Phosphorylation of SYNGAP1 is regulated by CaMKII, which reduces SYNGAP1's control of Ras-GTPase, leading to Ras activation by increasing the GTP-bound form of Ras. It is now established as a major signaling protein that plays a pivotal role in regulating fundamental molecular changes in dendritic spine synaptic morphological and functional modifications. Moreover, mutations in SYNGAP1 are established as relevant for human pathology, because they have been associated with ID comorbid with ASD in children (Hamdan et al., 2009, 2011a,b, 2014; Gauthier et al., 2011; Berryer et al., 2013).

Until a few years ago, the neurophysiological mechanism that causes ID in patients with SYNGAP1 mutation was not clear. Using mouse models of Syngap1 heterozygous mutations (Syngap $1^{-1+}$ ), several labs have shown that $50 \%$ reduction of the level of SYNGAP1 is sufficient to cause significant increases in the presence of mushroom-shaped dendritic spines during early stages of development resulting from a lack of inhibition of Ras-GTPase, which in turn allows more AMPARs to be transported to the postsynaptic membrane. Moreover, it has been shown that in Syngap1-/+ models certain critical periods of neuronal growth and maturation are disrupted, leading to developmental brain disorders, that in turn cause cognitive and social dysfunctions (Guo et al., 2009).

\section{Syngap1 EXPRESSION, FUNCTIONAL DOMAINS, AND ISOFORMS}

SYNGAP1 is a $\sim 140 \mathrm{kDa}$ protein, first characterized by Chen et al. (1998) using a mouse model of Syngap1 $1^{-/+}$mutation and followed by Kim et al. (1998) who developed a truncated form of SYNGAP1 using yeast two-hybrid system (See Table 1 for Historical perspective). Based on these studies, it can be understood that the N-terminal half of SYNGAP1 has a RasGAP domain, along with the region that is loosely homologous to Pleckstrin homology and a C2 domain which is potentially involved in binding of $\mathrm{Ca}^{2+}$ and phospholipids. Interestingly, the alignment of GAP domain of SYNGAP1 with other RasGAPs suggests that the amino acids in GAP domain are vital for interaction with Ras and for the stimulation of Ras-GTPase activity (Chen et al., 1998; Kim et al., 1998). Given the RasGAP-interacting domain of a newly discovered protein and its presence in excitatory synapses (Chen et al., 1998; Kim et al., 1998), this protein was termed SYNGAP1 (Synaptic RasGAP activator protein). Moreover, studies have shown that SYNGAP1 is expressed only in brain tissue and not in other tissues (Chen et al., 1998; Kim et al., 1998). In the brain, it is primarily expressed in the excitatory neurons, where it is localized to synapses. On the contrary, SYNGAP1 was absent

\footnotetext{
${ }^{1}$ http://www.ncbi.nlm.nih.gov/gene/8831
} 


\begin{tabular}{|c|c|c|}
\hline $\begin{array}{l}\text { SYGP1_HUMAN } \\
\text { SYGP1_RAT } \\
\text { SYGP1_MOUSE }\end{array}$ & $\begin{array}{l}\text { MSRSRAS I HRGS I PAMSYAPERDVRGPSMHRTQYVHSPYDRPGWNPRFCI ISGNQLLMLD } \\
\text { MSRSRAS I HRGS I PAMSYAPFRDVRGPPMHRTQYVHSPYDRPGWNPRFCI ISGNQLLMLD } \\
\text { MSRSRASI HRGS I PAMSYAPFRDVRGPPMHRTQYVHSPYDRPGWNPRFCI ISGNQLLMLD }\end{array}$ & 60 \\
\hline $\begin{array}{l}\text { SYGP1_HUMAN } \\
\text { SYGP1_RAT } \\
\text { SYGP1_MOUSE }\end{array}$ & $\begin{array}{l}\text { EDE IHPLLIRDRRSESSRNKLLRRTVSVPVEGRPHGEHEYHLGRSRRKSVPGGKQYSMEG } \\
\text { EDEIHPLLIRDRRSESSRNKLLRRTVSVPVEGRPHGEHEYHLGRSRRKSVPGGKQYSMEA } \\
\text { EDEIHPLLIRDRRSESSRNKLLRRTVSVPVEGRPHGEHEYHLGRSRRKSVPGGKQYSMEA }\end{array}$ & 120 \\
\hline $\begin{array}{l}\text { SYGP1_HUMAN } \\
\text { SYGP1_RAT } \\
\text { SYGP1_MOUSE }\end{array}$ & $\begin{array}{l}\text { ISTALRNPNIQRQPSRQSERPRPQPVVLRGPSAEMQGYMMRDLNSS IDLQSFMARGLNSS } \\
\text { ISTALRNPNIQRQPSRQSERARSQPMVLRGPSAEMQGYMMRDLNSS I DLQSFMARGLNSS } \\
\text { ISTALRNPNIQRQPSRQSERTRSQPMVLRGPSAEMQGYMMRDLNSSIDLQSFMARGLNSS }\end{array}$ & 780 \\
\hline $\begin{array}{l}\text { SYGP1_HUMAN } \\
\text { SYGP1_RAT } \\
\text { SYGP1_MOUSE }\end{array}$ & $\begin{array}{l}\text { AAGMRLSQMGVTTDGVPAQQLRIPLSFQNPLFHMAADGPGPPGGHGGGGGHGPPSSHHHH } \\
\text { AAGMRLSQMGVTTDGVPAQQLRIPLSFQNPLFHMAADGPGPPAGHGGSSGHGPPSSHHHH } \\
\text { AAGMRLSQMGVTTDGVPAQQLRIPLSFQNPLFHMAADGPGPPAGHGGSSGHGPPSSHHHH }\end{array}$ & 960 \\
\hline $\begin{array}{l}\text { SYGP1_HUMAN } \\
\text { SYGP1_RAT } \\
\text { SYGP1_MOUSE }\end{array}$ & $\begin{array}{l}\text { HHHHHHRGGEPPGDTFAPFHGYSKSEDLSSGVPKPPAAS I LHSHSYSDEFGPSGTDFTRR } \\
\text { HHHHHHRGGEPPGDTFAPFHGYSKSEDLSTGVPKPPAAS I LHSHSYSDEFGPSGTDFTRR } \\
\text { HHHHHHRGGEPPGDTFAPFHGYSKSEDLSSGVPKPPAASILHSHSYSDEFGPSGTDFTRR }\end{array}$ & 1020 \\
\hline $\begin{array}{l}\text { SYGP1_HUMAN } \\
\text { SYGP1_RAT } \\
\text { SYGP1_MOUSE }\end{array}$ & $\begin{array}{l}\text { QLSLQDNLQHMLSPPQITIGPQRPAPSGPGGGSGGGSGGGGGGQPPPLQRGKSQQLTVSA } \\
\text { QLSLQDNLQHMLSPPQITIGPQRPAPSGPGGGSGGGSGGGGGGQPPPLQRGKSQQLTVSA } \\
\text { QLSLQDSLQHMLSPPQITIGPQRPAPSGPGGGSGGGS---GGGQPPPLQRGKSQQLTVSA }\end{array}$ & $\begin{array}{l}1080 \\
1077\end{array}$ \\
\hline $\begin{array}{l}\text { SYGP1_HUMAN } \\
\text { SYGP1_RAT } \\
\text { SYGP1_MOUSE }\end{array}$ & $\begin{array}{l}\text { EIHSLKERLHMSNRKLEEYERRLLSQEEQTSKILMQYQARLEQSEKRLRQQQAEKDSQIK } \\
\text { EIHSLKERLHMSNRKLEEYERRLLSQEEQTSKILMQYQARLEQSEKRLRQQQVEKDSQIK } \\
\text { EIHSLKERLHMSNRKLEEYERRLLSQEEQTSKILMQYQARLEQSEKRLRQQQVEKDSQIK }\end{array}$ & 1260 \\
\hline $\begin{array}{l}\text { SYGP1_HUMAN } \\
\text { SYGP1_RAT } \\
\text { SYGP1_MOUSE }\end{array}$ & $\begin{array}{l}\text { SI IGRLMLVEEELRRDHPAMAEPLPEPKKRLLDAQERQLPPLGPTNPRVTLAPPWNGLAP } \\
\text { SI I GRLMLVEEELRRDHPAMAEPLPEPKKRLLDAQRGSFPPWVQQTRV------ } \\
\text { SI I GRLMLVEEELRRDHPAMAEPLPEPKKRLLDAQERQLPPLGPTNPRVTLAPPWNGLAP }\end{array}$ & $\begin{array}{l}1320 \\
1308 \\
1317\end{array}$ \\
\hline
\end{tabular}

FIGURE 1 | Amino acid sequence of human SYNGAP1 and its difference with mouse SYNGAP1. Amino acid sequence differences of SYNGAP1 between Homo sapiens (SYGP1_Human), Rattus rattus (SYGP1_RAT) and Mus musculus (SYGP1_MOUSE). Variations in the sequences were indicated in red colored fonts. Dashed line indicates empty sequences.

in inhibitory neurons. Chen et al. (1998) have shown that the carboxyl terminal tail of SYNGAP1 interacts with postsynaptic density protein (PSD-95), as confirmed by their coprecipitation (Kim et al., 1998). In addition, Kim et al. (1998) have shown that the C-terminal half consists of a repeat of 10 histidines that may be involved in metal chelation, several potential serine and tyrosine phosphorylation sites and a T/SXV motif necessary for interaction with SAP102 and PSD-95. This study further suggested that SYNGAP1 is a cytosolic protein without a signal peptide or any transmembrane domain (Kim et al., 1998).

Studies have shown that functionally distinct proteins may be produced via regulated alternate splicing of mRNA (Lipscombe, 2005; Li et al., 2007; Grabowski, 2011; Raj and Blencowe, 2015). It is evident that Syngap1 is a complex gene that gives rise to multiple protein domains. This further implies that Syngap1 may be spliced differentially, which can lead to different isoforms. Indeed, Chen et al. (1998) showed that two splice variants were observed, one at the amino terminus and one at carboxyl terminus, which further encode four variants with molecular weights of $134,137,140$ and $143 \mathrm{KDa}$. The amino acid terminal contains a putative Pleckstrin homology (PH) domain (Chen et al., 1998), which may attach the protein to the membrane (Lemmon and Ferguson, 2000). In support of this finding, a recent study has identified distinct isoforms of SYNGAP1 (Figure 2), differing in their N- and Cterminals (McMahon et al., 2012). The existence of different isoforms was further confirmed when anti-SYNGAP1 antibody recognized doublet or triplet of proteins at $130 \mathrm{kDa}$ only in the brain, with no detection of SYNGAP1 and its isoforms in any other parts of the body such as kidney, heart or lung (Chen et al., 1998; Kim et al., 2003). Each isoform contains a central GAP domain to regulate the activity of GTPase in small GTPases such as Ras and Rap. Three distinct Syngap1 isoforms, SYNGAP A, B and C, differing in their N-termini arising from different promoter regions have been identified (McMahon et al., 2012). A and B isoforms contain unique peptide sequence and a complete $\mathrm{PH}$ domain, whereas isoform $\mathrm{C}$ is a shorter, truncated protein with no unique peptide sequence and no $\mathrm{PH}$ domain. Furthermore, SYNGAP A, B, and C isoforms 
TABLE 1 | Historical perspective of major findings of SYNGAP1.

\begin{tabular}{|c|c|c|}
\hline Observation/findings of SYNGAP1 & Referrences & Model/samples \\
\hline First Syngap1 Het mouse model & Chen et al. (1998) & Mouse \\
\hline \multirow[t]{2}{*}{ Binds to CaMKII /PSD95 } & Chen et al. (1998) & Mouse \\
\hline & Kim et al. (1998) & Yeast two-hybrid hippocampal cDNA library \\
\hline \multirow[t]{4}{*}{ Amino acid sequences and molecular weight } & Chen et al. (1998) & Mouse \\
\hline & Kim et al. (1998) & Yeast two-hybrid hippocampal cDNA library \\
\hline & Husi et al. (2000) & Mouse \\
\hline & McMahon et al. (2012) & Mouse \\
\hline \multirow[t]{2}{*}{ Domain structure of SYNGAP1 and Isoforms } & Chen et al. (1998) & Mouse \\
\hline & McMahon et al. (2012) & Mouse \\
\hline \multirow[t]{3}{*}{ Localized in excitatory neurons } & Chen et al. (1998) & Mouse \\
\hline & Kim et al. (1998) & \\
\hline & Kim et al. (1998) & Yeast two-hybrid hippocampal cDNA library \\
\hline \multirow[t]{2}{*}{ Syngap1 Homozygous mice die within a week } & Komiyama et al. (2002) & Mouse/Primary neuronal culture \\
\hline & Kim et al. (2003) & Mouse/cortical culture \\
\hline \multirow[t]{2}{*}{ Synaptic transmission and LTP } & Komiyama et al. (2002) & Mouse/Primary neuronal culture \\
\hline & Kim et al. (2003) & Mouse/cortical culture \\
\hline Learning and Memory deficits & Komiyama et al. (2002) & Mouse/Primary neuronal culture \\
\hline \multirow[t]{2}{*}{ Altered ERK, Ras, Rac p-Cofilin } & Komiyama et al. (2002) & Mouse/Primary neuronal culture (ERK) \\
\hline & Carlisle et al. (2008) & Mouse/Hippocampi neuronal culture \\
\hline \multirow[t]{2}{*}{ Dendritic spine structure } & Vazquez et al. (2004) & Mouse/primary neuronal culture \\
\hline & Carlisle et al. (2008) & Mouse/Hippocampi neuronal culture \\
\hline \multirow[t]{2}{*}{ Cognitive and social dysfunction } & Guo et al. (2009) & Mouse \\
\hline & Muhia et al. (2010) & Mouse \\
\hline Intellectual disability in children & Hamdan et al. (2009) & Human \\
\hline \multirow[t]{2}{*}{ Prematuration of dendritic spines } & Clement et al. (2012) & Mouse \\
\hline & Aceti et al. (2015) & Mouse (in vivo) \\
\hline Altered critical period of plasticity & Clement et al. (2013) & Mouse \\
\hline
\end{tabular}

This table summarizes the major findings/observations of function of SYNGAP1 by various groups.

can be subdivided based on transcription start sites (A1-A11; $\mathrm{B} 1$; $\mathrm{C} 1-\mathrm{C} 8)$. To determine whether the multiple promoters were also present in humans, a sequence comparison with mouse and rat revealed a highly conserved regions with no predicted functional moieties (McMahon et al., 2012). Finally, alternate splicing of Syngap1 mRNA leads to multiple isoforms of Ctermini, designated as $\alpha, \beta$ and $\gamma$. Of these, the most studied C-terminus isoform is SYGNAP1 $\alpha 1$, which contains the PDZbinding domain and mediates binding to scaffolding proteins of PSD.

The expression of various genes that encode proteins regulating synaptic formation and function are shown to reach their peak level of expression during early stages of development. Moreover, several of these proteins have recently been implicated in ID (State and Levitt, 2011; State and Sestan, 2012). Indeed, expression of SYNGAP1 in neurons reaches its peak 14 days after birth, i.e., at Postnatal day 14 (PND 14 days) in rodents (Kim et al., 1998; Clement et al., 2012), but steadily decreases to adult level by 2 months of age (Porter et al., 2005). Further, SYNGAP1 is highly expressed in hippocampus and cortex, and less in striatum (Komiyama et al., 2002). The expression of SYNGAP1 was reduced by $50 \%$ in Syngap1 $1^{-/+}$mice (Komiyama et al., 2002; Kim et al., 2003; Clement et al., 2012). However, no abnormal gross development of brain was observed in Syngap $1^{-/+}$mice (Kim et al., 2003).

It is well known that development and synaptic activity plays a major role in differential splicing of genes involved in synaptic function. The N-termini SYNGAP1 isoforms, A and B had a pattern of regulation during development (gradual increase in expression till PND14), while isoform $\mathrm{C}$ was expressed at very low level till PND14 (McMahon et al., 2012). However, all three isoforms, A, B, and $\mathrm{C}$ reached their peak expression at PND14. Further, it is shown that Syngap B and C were upregulated two-fold after $4 \mathrm{~h}$ of bicuculline treatment, whereas SYNGAP A was down-regulated (McMahon et al., 2012). These changes were inhibited in the presence of tetrodotoxin. This confirms that differential splicing of Syngap1 occurs based on neuronal activity, which leads to opposing functional effects of Syngap1 isoforms; SYNGAP A had silencing effect, while SYNGAP B and C had positive effect on synaptic transmission and strength. Unlike N-termini isoforms, the protein levels of C-termini isoforms did not change when stimulated with bicuculline. Importantly, it is not clear from previous studies which combination of $\mathrm{N}$ - and $\mathrm{C}$ - termini isoforms exists in neurons. Using isoform-specific antibodies, it is clear that both C-terminal isoforms exist in hippocampus and cortex (McMahon et al., 2012; Yang et al., 2013) and that $\alpha 2$-containing isoforms localize to PSDs, although they do not contain a QTRV region to bind to PDZ domain. This could be because, when non-phosphorylated CaMKII is inactive at rest, both isoforms are localized within PSD core and $\alpha 1$ binding to PSD-95 serves a distinct function, that of blocking the other portions from binding to PSD-95. Furthermore, upon activation of NMDARs, both $\alpha 1$ and $\alpha 2$ isoforms move out of the PSD core, but this change was reversed within 30-45 min following the NMDAR activation. 


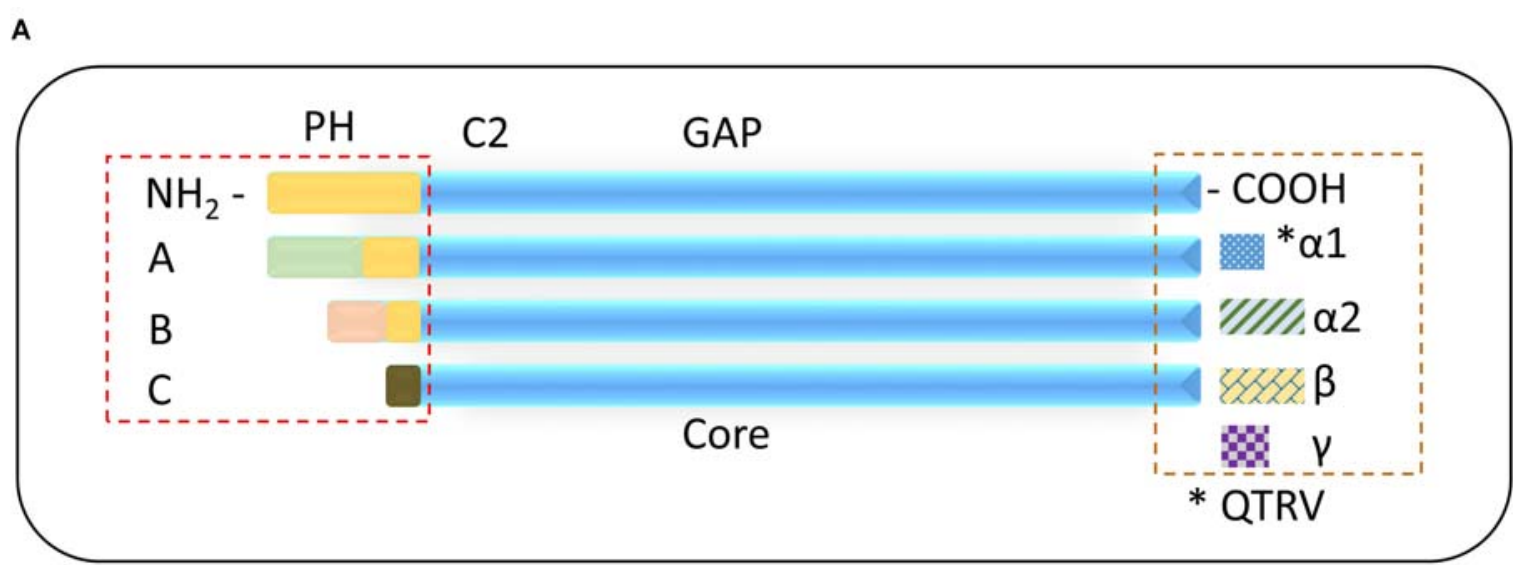

B

SYNGAP A MSRSRASIHRGIPAMSYAPFRDVRGPPMHRTQYVHSPYDRPGWNPRFCIISGNQLLMLDEDEIHPLLIRDRRSESSRNKLLRRTVSVPVEGRPHGEH SYNGAP B $\ldots \ldots \ldots$. $\ldots$ C.

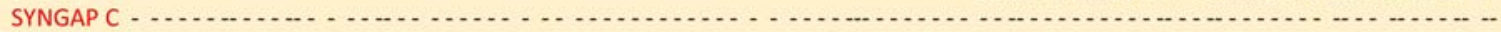

SYNGAP A EYHLGRSRRKSVPGGKQYSMEAAPAAPFRPSQGFLSRRLKSSIKRTKSQPKLDRTSSFRQILPRFRSADHDRARLMQSFKESHSHESLLSPSSAAEAL SYNGAP B EYHLGRSRRKSVPGGKQYSMEAAPAAPFRPSQGFLSRRLKSSIKRTKSQPKLDRTSSFRQILPRFRSADHDRARLMQSFKESHSHESLLSPSSAAEAL SYNGAP C $\ldots \ldots \ldots$ MQ

Alpha1 VKEYEEEIHSLKERLHMSNRKLEEYERRLLSQEEQTSKILMQYQARLEQSEKRLRQQQVEKDSQIKSIIGRLMLVEEELRRDHPAMAEPLPEPKKRLLDAQ Alpha2 VKEYEEEIHSLKERLHMSNRKLEEYERRLLSQEEQTSKILMQYQARLEQSEKRLRQQQVEKDSQIKSIIGRLMLVEEELRRDHPAMAEPLPEPKKRLLDAQ GammaVKEYEEEIHSLKERLHMSNRKLEEYERRLLSQEEQTSKILMQYQARLEQSEKRLRQQQVEKDSQIKSIIGRLMLVEEELRRDHPAMAEPLPEPKKRLLDAQ Beta VKEYEEEIHSLKERLHMSNRKLEEYERRLLSQEEQTSKILMQYQARLEQSEKRLRQQQVEKDSQIKSIIG . . . . . . . . . . . . . . . . . . . .

\section{Unique C-terminal Sequences}

\section{Alpha1 RGSFPPWVQQTRV}

Alpha2 VERQLPPLGPTNPRVTLAPPWNGLAPPAPPPPPRLQITENGEFRNTADH

Gamma LLIR

Beta SPSLQADAGGGGAAPGPPRHG

FIGURE 2 | SYNGAP1 isoforms arising from alternate splicing. (A) A schematic illustration of potential SYNGAP1 isoforms, which vary in both N-and C-termini. (B) Amino acid sequences that are unique to different N- and C-termini isoforms identified by mass spectrometry (McMahon et al., 2012).

This movement of SYNGAP1 $\alpha 1$ and $\alpha 2$ out of PSD core could have two significant effects. The first major effect could be a displacement of GAP activity and thus induces activity-dependent synaptic modification (Yang et al., 2013; Araki et al., 2015). The second major effect of SYNGAP1 $\alpha 1$ and $\alpha 2$ isoforms moving out of the PSD core is to create an empty slot for the association of an AMPAR (Yang et al., 2013), thereby regulating synaptic strength. In fact, overexpression of SYNGAP1 $\alpha 1$ isoform reduces AMPAR-mediated miniature excitatory postsynaptic currents (mEPSCs), whereas overexpression of SYNGAP1 $\alpha 2$ isoform enhances mEPSCs. Nevertheless, these studies illustrate the fact that different isoforms exert opposing effects on synaptic strength and that both full peptide sequences, $\mathrm{N}$ - and C-terminal, and their isoforms must be considered when examining the functional properties of the protein.

\section{SYNGAP1 MUTATIONS IN INTELLECTUAL DISABILITY}

ID, formerly characterized as Mental Retardation, is defined by three criteria: (a) an intelligent quotation of less than 70 ; (b) limitations in two or more adaptive behaviors such as communication, self-care and social skills, community use, selfdirection, health, and safety; and (c) evidence that the mental manifestations began before the age of 18 (van Bokhoven, 2011). ID comprises a diverse collection of syndromic and non-syndromic disorders. Unlike NSID, which is characterized by intellectual deficits as the only clinical feature, syndromic ID patients typically exhibit other abnormal clinical features, such as cranial, facial, and skeletal dysmorphisms. Major causes of ID and ASD stem from mutations of genes encoding for proteins that are critical regulators of synaptic function. De novo mutations in individual genes explain an important aspect of 
NSID characterized by the absence of associated morphologic, radiologic and metabolic features, as opposed to ID associated with more complex chromosomal aberrations (Ropers and Hamel, 2005). The genetic factors involved in NSID are not clearly known. So far, 29 X-linked and five autosomal recessive genes have been identified by linkage and cytogenetic analysis (Bienvenu and Chelly, 2006; Chelly et al., 2006; Gécz et al., 2009). In addition, mutations in autosomal dominant genes are still to be identified in NDDs, as ID and ASD result in lower reproductive probability, which further reduces the chances of identifying families that are open to linkage analysis. Yet, de novo mutations are the most commonly recognized cause of ID, which suggests that monoallelic lesions are sufficient to cause this disorder. In fact, studies have shown that one to three de novo mutations per zygote affect amino acid sequences (Crow, 2000a,b, 2006).

In the past decade, novel autosomal de novo mutations were identified in genes encoding for proteins involved in synaptic plasticity. In relation to that, recent studies from children have shown that de novo truncating mutations in SYNGAP1 cause NSID (Hamdan et al., 2009, 2011a,b, 2014; Berryer et al., 2013). Hamdan et al. (2009) identified protein-truncating de novo mutations in SYNGAP1 in 3 of 94 patients with NSID. These patients ranged from $4-11$ years and had similar clinical features as described in the Mullen Scale of Early Learning and the Vineland Adaptive Behavior Scales (Hamdan et al., 2009). Of those three patients, two patients were heterozygous for nonsense mutations, while the third patient was heterozygous for a frameshift mutation starting at codon 813 , producing a premature stop codon at 835 . All these children were born to nonconsanguineous parents. During early stages of development, these children presented with hypotonia and global delay of development with the onset of walking at 2-years. Apart from these defects, two of these children had presented with tonicclonic and myoclonic seizures.

In order to further explore the association of SYNGAP1 to ID, particularly to understand whether patients with epilepsy and ASD had SYNGAP1 de novo mutations, Hamdan et al. (2011a) sequenced exons of SYNGAP1 from additional cohorts of patients. De novo out-of-frame deletions were identified in two patients with NSID presented with microcephaly and generalized epilepsy. The authors also described a de novo splicing mutation in a patient with autism that had not acquired microcephaly or epilepsy (Refer to Table 2). Moreover, missense mutations in SYNGAP1 were detected in three patients. Surprisingly, all these patients were born to non-consanguineous parents. Furthermore, other studies (Krepischi et al., 2010; Zollino et al., 2011; Writzl and Knegt, 2013) have identified de novo microdeletions in chromosome region $6 \mathrm{p} 21.3$ in patients with ID, epilepsy and severe language impairment. Therefore, it is evident from the studies that heterozygous mutations in SYNGAP1 are the major cause of NSID.

\section{SYNGAP1 IN SCHIZOPHRENIA}

Although several studies have shown the role of Syngap1 mutations in neurodevelopmental disorders, a little is known about its relevance to schizophrenia. Converging evidence suggest that dysfunction of NMDARs and the signaling complex associated with them is now considered to be one of the major causes of schizophrenia (Belsham, 2001). Hypofunction of NMDARs was first implicated when reduced concentration of glutamate were found in the cerebrospinal fluid of patients with schizophrenia (Kim et al., 1980). The alteration in the function of activation-ready NMDAR complexes localized in the PSD can lead to a defect in downstream signaling pathways. It has been shown that a major function of SYNGAP1 is to transduce the activation of synaptic NMDA receptors to a biochemical signal that is necessary for proper neuronal function. Therefore, SYNGAP1 and its interacting proteins may be abnormal in patients with schizophrenia.

A study by Funk et al. (2009) has shown that SYNGAP1 and its interacting proteins, such as PSD95, were reduced in patients with schizophrenia. Interestingly, patients who were non-medicated for 6 weeks prior to the time of their death showed decreased levels of SYNGAP1 compared to medicated patients. A similar observation was made for SYNGAP1interacting proteins such as PSD-95. This study hypothesized that $S Y N G A P 1^{-/+}$are associated with schizophrenia-like behavioral phenotypes. Indeed, reduced expression of SYNGAP1 results in abnormal behaviors that are strikingly similar to that reported in mice with reduced NMDAR function (Guo et al., 2009). This suggests that proteins downstream of NMDAR, including SYNGAP1, participate in a common pathway that may be dysfunctional in people with schizophrenia. However, other studies (Hamdan et al., 2009) did not find any de novo mutations, splicing or truncating, in their patients with schizophrenia. As the sample number of patients with schizophrenia studied in their work is low, more samples are needed to confirm the role of SYNGAP1 Het in schizophrenia.

\section{MOUSE MODELS OF Syngap1}

The recent advances in genomic science and the development of transgenic technology in mice have advanced research into the effect of monoallelic mutations in genes that are associated with synaptic transmission and neuronal circuit formation. SYNGAP1 is highly conserved across species (McMahon et al., 2012), which has allowed for the development of different animal models of Syngap1 $1^{-/+}$mice (Komiyama et al., 2002; Kim et al., 2003; Vazquez et al., 2004; Muhia et al., 2010). The SYNGAP1 mouse ortholog, Syngap1, is located on chromosome $17^{2}$. Interestingly, Syngap1 $1^{-/-}$mutant mice do not survive for more than a week (Kim et al., 2003). This is due to increased levels of caspase-3 activation in Syngap1 ${ }^{-/-}$, which suggests that apoptosis is enhanced by reduction of SYGNAP1 (Knuesel et al., 2005). The different animal models of Syngap1 $1^{-1+}$ are extensively discussed in a recent review (Ogden et al., 2015).

\footnotetext{
${ }^{2}$ http://www.ncbi.nlm.nih.gov/gene/240057
} 
TABLE 2 | Clinical features observed in patients with SYNGAP1 heterozygous mutation.

\begin{tabular}{|c|c|c|c|c|c|c|c|}
\hline Patient no & Gene & DNM & Age & Sex & ID & Epilepsy & Cranial MRI/CT \\
\hline 1 & SYNGAP1 & p.Lys138X & 4 yrs. 5 months & $\mathrm{F}$ & $++/+++$ & GN & Normal/ND \\
\hline 2 & SYNGAP1 & p.Arg579x & 5 yrs. 10 months & $\mathrm{F}$ & $++/+++$ & GN & Normal/ND \\
\hline 3 & SYNGAP1 & p.Leu813ArgfsX23 & 12 yrs. 10 months & $\mathrm{F}$ & $++/+++$ & - & ND/Normal \\
\hline 4 & STXBP1 & p.Arg388X & 15 yrs. & $\mathrm{F}$ & +++ & $\mathrm{PC}$ & Normal/Normal \\
\hline 5 & STXBP1 & c. $169-1 G>A$ & 27 yrs. & $\mathrm{F}$ & +++ & $\mathrm{PC}$ & ND/Normal \\
\hline 6 & SHANK3 & c. $601-1 G>A$ & 15 yrs. & $M$ & + & - & ND/Normal \\
\hline 7 & KIF1A & p.Thr99Met & 3 yrs. 5 months & $\mathrm{F}$ & +++ & - & Atrophy/ND \\
\hline 8 & GRIN1 & p.Glu662Lys & 10 yrs. & $\mathrm{F}$ & ++ & - & ND/Normal \\
\hline 9 & GRIN1 & p.Ser560dup & 7 yrs. 6 months & $\mathrm{M}$ & +++ & PC & Normal/ND \\
\hline 10 & EPB41L1 & p.Pro854Ser & 6 yrs. & $M$ & +++ & - & Normal/ND \\
\hline 11 & CACNG2 & p.Val143Leu & $8 \mathrm{yrs}$. & $M$ & ++ & - & Normal/ND \\
\hline 12 & KIFC1, PHF1, CUTA, SYNGAP1 & - & 6 yrs. & M & ++ & - & Normal/ND \\
\hline 13 & SYNGAP1, CUTA, PHF1 & - & 5 yrs. & $\mathrm{F}$ & +++ & GN & Normal/ND \\
\hline 14 & SYNGAP1, CUTA, PHF1 & - & 9 yrs. & M & ++ & $\mathrm{PC}$ & Normal/ND \\
\hline
\end{tabular}

Summary of clinical features observed in patients with SYNGAP1 heterozygous mutation. ID Scale: + denotes mild, ++ moderate, +++ severe. Abbreviations used ND, not determined; PC, Partial complex epilepsy; GN, Generalized epilepsy. These features are based on different sources (Hamdan et al., 2009, 2011a,b, 2014; Krepischi et al., 2010; Zollino et al., 2011; Berryer et al., 2013; Writzl and Knegt, 2013).

Due to a rapid increase in the availability of the types of genetically modified mice (Branchi et al., 2003), it is critical to meticulously characterize their biochemical, pathological and behavioral features and compare them with human phenotypes (Bailey et al., 2006; Crawley, 2008). Generally, laboratories involved in testing the phenotypes of genetically modified mice subject them to a battery of behavioral features to assess cognitive, motor, and sensory functions. In addition, to consider a genetically modified mouse as a disease model, the transgenic animal must fulfil at least two levels of validity to judge its psychopharmacology (van der Staay et al., 2009). An animal model should score high on the following validities: face validity, i.e., resemblances of behavioral phenotypes of mouse model to that of human disorder; construct validity, i.e., closely reconstructs and mimics the underlying cause of the disease or disorder; and predictive validity, i.e., drug treatments alleviate symptoms in mouse and human. A mouse model should fulfil at least face and construct validity. Indeed, various mouse models of Syngap1 $1^{-/+}$mice satisfied face validity (Komiyama et al., 2002; Kim et al., 2003; Guo et al., 2009; Muhia et al., 2010). These various Syngap1 $1^{-/+}$mouse models recapitulated many of the phenotypes observed in humans. For example, Komiyama et al. (2002) were the first to observe learning and memory deficits in Syngap $1^{-/+}$mice. Using a different model described by Kim et al. (2003), Syngap1 $1^{-/+}$ mice displayed altered social/conspecific interaction, abnormal spatial working memory, decreased anxiety-related response, hyperactivity, impaired cued conditioning behavior, increased startle reflex, increased horizontal stereotypic behavior and reduced prepulse inhibition, as well as learning deficits (Guo et al., 2009). Later, using another genetic model of Syngap1 $1^{-/+}$ mice (Muhia et al., 2010), Muhia et al. observed cognitive dysfunctions similar to the Guo et al. (2009) study. As mentioned previously, epilepsy is a prominent clinical feature observed in SYNGAP1 patients. Accordingly, Syngap1 $1^{-/+}$mice are prone to audiogenic seizures and have reduced seizure threshold and altered electroencephalogram (EEG; Clement et al., 2012; Ozkan et al., 2014). Therefore, based on these studies, it is clear that mouse models of Syngap1-/+ (Ogden et al., 2015) mutation phenocopy the deficits observed in SYNGAP1 patients, thereby allowing a better understanding of $S Y N G A P 1^{-/+}$mutation in neuronal function and its consequence in ID.

\section{ROLE OF Syngap1 IN NEUROLOGICAL PATHWAY}

For nearly two decades, neuroscientists have studied SYNGAP1related signaling pathways. Synapses are extremely ordered structures that facilitate the transmission of information from presynaptic terminal to the postsynaptic membrane and, subsequently, activate signal transduction cascades that lead to suitable cellular events. In the postsynaptic membrane, two major ionotropic glutamate receptor subtypes are present-NMDARs and AMPARs. NMDARs are glutamate-sensitive ion channels that open up when glutamate and its co-agonist are bound to them. However, the actual permeation of ions through NMDAR channels occurs after the removal of $\mathrm{Mg}^{2+}$ block achieved by depolarization of the postsynaptic membrane. This depolarization is induced by glutamate binding to AMPARs. Subsequently to activation of NMDARs in the postsynaptic membrane, $\mathrm{Ca}^{2+}$ enters the dendritic spine, triggering activation of kinase cascades and thereby mediating various synaptic functions (Fan et al., 2014). NMDARs are an integral component of the PSD and bind to several PSD-enriched scaffold and signaling molecules, resulting in creation of a vast protein complex (Niethammer et al., 1996; Kennedy, 1997; Xu, 2011). This NMDAR-PSD protein complex is believed to play a vital role in the precise tuning of synapses in response to changing input stimuli pattern (Grant and O'dell, 2001; Yashiro and Philpot, 2008). SYNGAP1, one of the most abundant proteins in the PSD, is associated with NMDAR protein complex (Figure 3), which was first shown by Chen et al. (1998) and followed by Kim et al. (1998). Establishing SYNGAP1's role in the 
NMDAR-mediated protein complex and signaling cascade is important to further our understanding of the etiology of SYNGAP1-mediated ID and ASD (Figure 3). SYNGAP1 has been shown to co-immunoprecipitate with PSD-95 protein complex from deoxycholate-solubilized mouse brain membrane preparations (Chen et al., 1998; Kim et al., 1998).

The GAP domain of SYNGAP1 is homologous to that of p120GAP and neurofibromin, two canonical Ras-GAPs that do not regulate Rap (Chen et al., 1998; Kim et al., 1998). However, SYNGAP1 has been shown to regulate RapGTPase more potently than Ras-GTPase (Pena et al., 2008). A recent study by Walkup et al. (2015) has shown that recombinant SYNGAP1 lacking 102 residues at the $\mathrm{N}$-terminus is phosphorylated by cyclin-dependent kinase 5 (CDK5), as well as by CaMKII. Interestingly, phosphorylation of SYNGAP1 by CDK5 and CaMKII increases overall SYNGAP1 activity, but also alters the ratio of its GAP activity towards Rasand Rap-GTPases. Phosphorylation of SYNGAP1 by CaMKII increases its Ras-GAP activity by $25 \%$ and its Rap-GAP activity by $76 \%$. CDK5 increases recombinant SYNGAP1 activity on Ras-GAP by $98 \%$ and its Rap-GAP activity by $20 \%$. Furthermore, upon NMDAR stimulation, $\mathrm{Ca}^{2+}$ entering the synapse dissociates CaMKII from SYNGAP1 and phosphorylates SYNGAP1 (pSYNGAP1). This leads to activation of Ras that activates proteins downstream, consequently to AMPAR insertion in the postsynaptic membrane. Therefore, the phosphorylation of SYNGAP1 is believed to be important in regulating transient changes in the number of surface AMPA receptors or gradually adjusting their steady-state level.

By biochemical analysis of proteins containing the GAP, Krapivinsky et al. (2004) have identified the C2 domain as essential for the Rap-GAP activity of SYNGAP1, which is in line with the recent observation (Walkup et al., 2015). The homology of SYNGAP1 with other Ras-GAP domains across species and in vivo associations of SYNGAP1 with the NMDA receptor complex indicate that SYNGAP1 plays a role in Ras-mediated signaling in excitatory synapses, particularly in response to $\mathrm{Ca}^{2+}$ (Kim et al., 1998; Carlisle et al., 2008). Apart from regulating Rasmediated signaling, SYNGAP1 has been shown to mediate the activity of other major signaling proteins, such as Rac, p-Cofilin, p21-activated kinase (PAK) and LIMK (Carlisle et al., 2008) and these proteins were shown to be elevated at basal conditions in Syngap $1^{-/+}$mice.

\section{ROLE OF SYNGAP1 IN REGULATING DENDRITIC SPINE MORPHOLOGY AND PLASTICITY}

The neuronal signaling cascades underlying synaptic plasticity and dendritic spine structure have been intensely studied and a multitude of signaling molecules have been identified (Kennedy et al., 2005; Patterson and Yasuda, 2011). Initial stages of dendritic spine formation and neuronal connections depend on cytoskeleton protein, F-actin, which is regulated by Rasand Rac-GTPases. Therefore, it is possible that the dendritic spine structure and function would be altered in Syngap1 $1^{-/+}$ mutations, which may explain the behavioral deficits observed in SYNGAP1 $1^{-/+}$patients.

Ras- and Rac-mediated signaling cascade, including ERK and MAPK, has also been shown to play a major role in normal synaptic transmission and in long-term potentiation (LTP; Carlisle and Kennedy, 2005; Kennedy et al., 2005) by modulating insertion of AMPARs into the postsynaptic membrane (Figure 3). On the contrary, opposite effects were observed in Syngap1 knockout in neuronal cultures using small interfering RNA. Studies from neuronal culture have demonstrated that overexpression of Syngap1 resulted in a remarkable down regulation of AMPAR-mediated currents (Rumbaugh et al., 2006). In contrast, AMPAR-mediated currents were increased in Syngap $1^{-/+}$in neuronal cultures treated with small interfering RNA.

Under basal conditions, when fEPSPs, which are predominantly mediated by AMPARs, were measured from adult mouse CA1 hippocampal pyramidal region, Syngap1 $1^{-/+}$ mice did not show any abnormal excitatory synaptic responses (Komiyama et al., 2002). Furthermore, the presynaptic fibers were required to evoke an equivalent postsynaptic response in slices from wild type (WT), and Syngap1 $1^{-/+}$mouse responses were not altered suggesting that the activity of postsynaptic AMPARs were unchanged. However, these experiments were performed in adults and the genes encoding the proteins that regulate synaptic function reach their peak level of expression during early stages of development (State and Levitt, 2011; State and Sestan, 2012). Indeed, Syngap1 Het mutations can affect synaptic transmission during early developmental period. Thus, Vazquez et al. (2004) have reported that the Syngap1 $1^{-/+}$ mice form dendritic spines and synapses prematurely, and that spines ultimately become larger in Syngap $1^{-/+}$. In addition, Clement et al. $(2012,2013)$ have shown elevated input-output relationship in extracellular field recording and AMPARmediated mEPSCs, which reached WT adult level 2 weeks after birth (PND14), confirming the earlier findings (Vazquez et al., 2004). These studies suggest that SYNGAP1 controls the trajectory of synapse maturation during a particular period of development by controlling protein synthesis and homeostatic synaptic plasticity during development (Wang et al., 2013).

In hippocampal pyramidal neurons, spine structure is tightly correlated with synaptic function (Noguchi et al., 2011). Syngap1 $1^{-/+}$mutation disrupts proper development of dendritic spine structures. Syngap1 $1^{-/+}$mice have more mature, mushroom-shaped spines during early stages of development (PND14) suggesting precarious prematuration of dendritic excitatory spine structures (Clement et al., 2012, 2013). Further, accelerated spine formation and premature spine pruning have been observed in developing neocortical tissue of Syngap1 $1^{-/+}$ mice (Aceti et al., 2015). These abnormalities observed during development in Syngap1 $1^{-/+}$mutation persisted into adulthood (Vazquez et al., 2004; Carlisle et al., 2008; Clement et al., 2012), consistent with the spine dysfunction theory of cognitive disorders. 


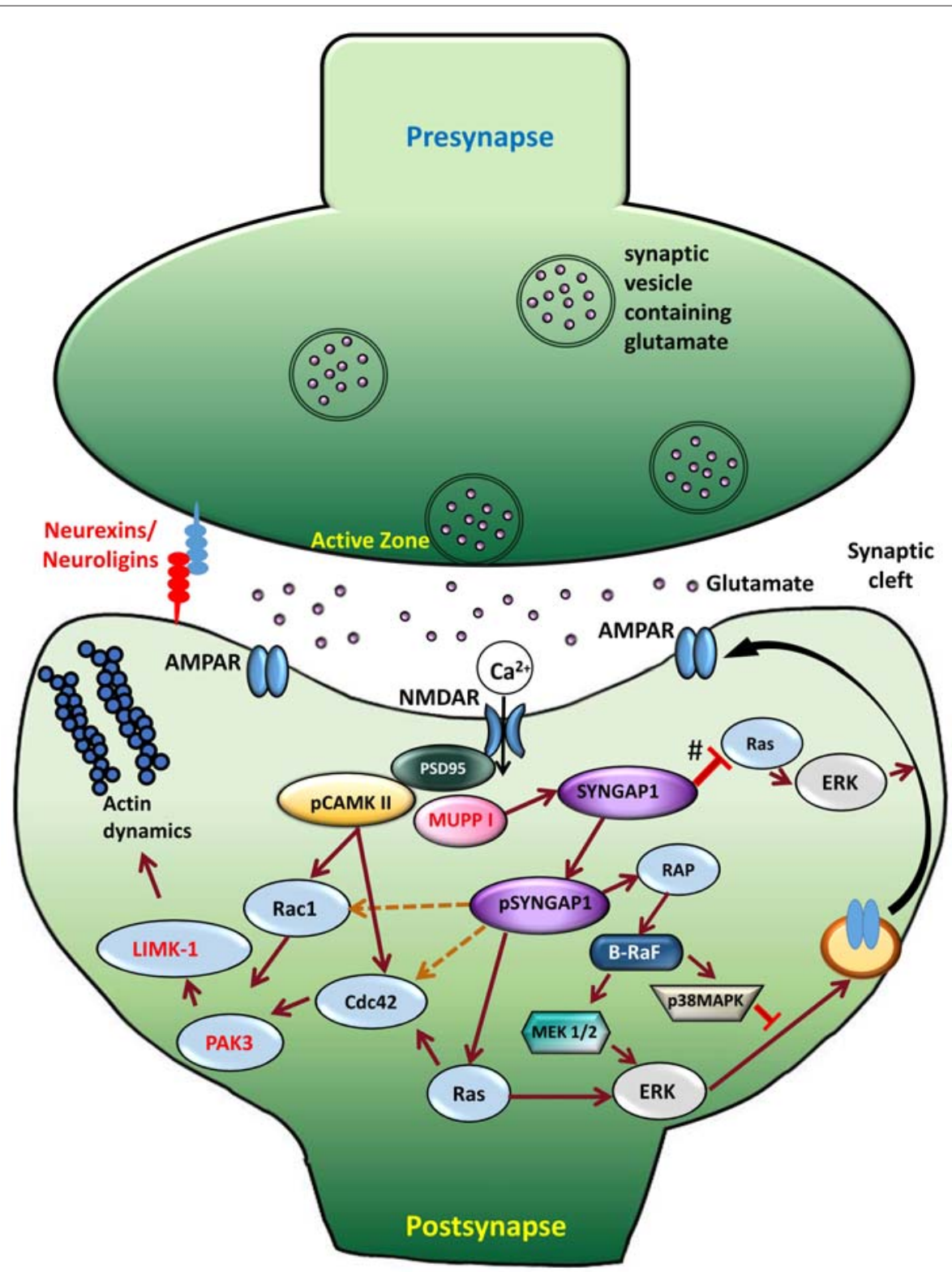

FIGURE 3 | Signaling mechanism upon phosphorylation of SYNGAP1. Schematic model of the cellular events that link CaMKIl activity to phosphorylation of SYNGAP1 and its regulation of downstream molecules. Glutamate receptors, such as NMDAR and AMPAR, are clustered at the postsynaptic active zone with a dense matrix called PSD. Upon NMDAR activation, $\mathrm{Ca}^{2+}$ enters the postsynaptic cytosol, triggering phosphorylation of CaMKIl, which in turn phosphorylates SYNGAP1 (pSYNGAP1). pSYNGAP1 regulates Ras-GTPases controlling actin dynamics and AMPARs insertion into the postsynaptic membrane. In Syngap1 Heterozygous mutation, the inhibition of Ras activation by SYNGAP1 (shown as \#) is lost, which increases Ras activity, thereby increasing AMPAR exocytosis to the postsynaptic membrane. Phosphorylation of SYNGAP1 by cyclin-dependent kinase 5 (CDK5) activates Rap1 that increases endocytosis of AMPAR. It is not clear how pSYNGAP1 regulates other SYNGAP1-associated proteins such as Cdc42, Rac1 (dotted orange lines), which are yet to be studied.

Altered maturation of dendritic spine morphology and function can lead to various learning and memory deficits (Peca et al., 2011; Goncalves et al., 2013). Indeed, patients with SYNGAP1 Het mutations were observed to have learning and memory deficits (Hamdan et al., 2009, 2011a). To understand the impact of early maturation of dendritic spine morphology and function on learning and memory in Syngap $1^{-/+}$mice, synaptic plasticity studies were carried out by various labs. There are two major forms of synaptic plasticity, LTP and LTD (long term depression), which have been considered to represent the cellular correlates of learning and memory and are both dependent on local protein synthesis (Volianskis et al., 2015). Deficits in LTP have been observed in many animal models of ID and ASD (Volk et al., 2007, 2015; Pavlowsky et al., 2012). Alterations in signaling proteins function can lead to anomalous synaptic plasticity and dendritic spine structure and can correlate with 
cognitive impairments in patients with ID and ASD (McKinney, 2005; Penzes et al., 2011; van Bokhoven, 2011; Kroon et al., 2013). Interestingly, adult Syngap1 $1^{-/+}$mice do show reduced LTP in the CA1 hippocampal region, which is likely due to reduced activation of Ras and ERK during LTP (Komiyama et al., 2002; Kim et al., 2003; Ozkan et al., 2014), suggesting that reduced level of SYNGAP1 derepresses the resting levels of activated Ras and ERK. Additionally, SYNGAP1 has been shown to rapidly disperse from spines during and after LTP because of the phosphorylation of SYNGAP at Ser1108/1138 by CaMKII. Subsequently, SYNGAP1 activates Ras, which triggers long-term changes in spine size, suggesting the inhibition of stable LTP by SYNGAP1 (Araki et al., 2015).

\section{CRITICAL PERIOD OF PLASTICITY}

Steady increase of synaptic AMPARs and subsequent functional unsilencing of glutamatergic inputs are characteristics of early postnatal development (Kerchner and Nicoll, 2008). Premature acquisition of functional AMPARs during development is suggestive of an acceleration of neurodevelopmental pattern during a critical period of development. A critical period is a regulated time window during which the sensory experience and intrinsic neuronal activity provide information that are essential for normal development and refinement of neuronal circuits (Meredith et al., 2012). Any alteration to dendritic spine structure and function during this critical period can have a lasting effect on cognitive functions, the development of which requires the formation and refinement of synaptic networks of neurons in the brain. Precariously high AMPAR/NMDAR ratios observed in Syngap1 $1^{-/+}$mice could lead to altered duration of plasticity-related critical periods. In the thalamocortical pathway, generation of LTP becomes difficult towards the end of the first postnatal week (Crair and Malenka, 1995). However, high frequency stimulation failed to elicit LTP in PND4 and PND7 in Syngap $1^{-/+}$mice, while LTP was generated in PND4 WT animals. Given that SYNGAP1 has been shown to suppress AMPAR insertion in the postsynaptic membrane, the main explanation for LTP failure at synapses would be a precocious unsilencing of the developing thalamocortical pathway. Indeed, Syngap $1^{-/+}$mice have altered unsilencing of post-synapses during early stages of development in the thalamocortical pathway (Clement et al., 2013) and altered formation and elimination of dendritic spines (Aceti et al., 2015). These studies further confirm the hypothesis that prematuration of dendritic spine structure due to accumulation of AMPAR at synapses shortens the duration of the critical window of plasticity leading to altered behavioral function (Figure 4).

In addition to LTP, another form of synaptic plasticity, LTD is important for proper formation and refinement of neuronal connections (Feldman and Knudsen, 1998; Hensch, 2005). Thus, it would be predicted that thalamocortical synapses exhibits LTP as well as LTD. Similar to LTP, the amount of LTD induced in thalamocortical connections exhibited a developmental reduction with little or no depression remaining by P10-12 (Feldman et al., 1998). This signals the end of critical period of plasticity in thalamocortical synapses. In addition, this study suggests that NMDAR dependent LTD modulates the efficacy of synapses previously unsilenced by LTP (Daw et al., 2007), thereby, allowing the synapses to modulate the connections based on the input specific activity. However, it is not clear LTD can induce resilencing of functional synapses during critical period of development. Given the importance of LTD in critical period of plasticity, it is not clear whether LTD is altered during critical period of development in Syngap $1^{-/+}$mice.

\section{PROPOSED MODEL OF Syngap1-/+ MUTATION IN NEURONAL DEVELOPMENT AND MATURATION}

One of the common features observed in most forms of ID is the inability to develop and maintain normal dendritic spine architecture and proper function at synapses, which lead to abnormal neuronal connections. Based on the above discussion, it is evident that Syngap1 $1^{-/+}$mutations lead to abnormal dendritic spine maturation during development. All mutations in Syngap1 are predicted to truncate the protein, thus decreasing the ability of SYNGAP1 to bind to the molecules downstream in the signaling pathway. Phosphorylation of SYNGAP1 is regulated by CaMKII, which reduces SYNGAP1's control of Ras-GTPase, leading to Ras activation by increasing the GTP-bound form of Ras. Further, phosphorylation of SYNGAP1 by CaMKII increases the ratio of Rap1-GAP to Ras-GAP (Walkup et al., 2015). This would shift the steady-state balance of AMPAR trafficking at the synapse towards exocytosis by decreasing the level of active Rap1 compared to active Ras, which would result in an increased surface AMPAR. In contrast, phosphorylation of SYNGAP1 by CDK5 decreases its ratio of Rap1-GAP to Ras-GAP activity, which would allow more AMPAR to be endocytosed from the postsynaptic surface. Therefore, SYNGAP1 negatively regulates Ras activation and insertion of AMPA receptors in the postsynaptic membrane. Phosphorylation of SYNGAP1 creates transient changes in the number of AMPARs and gradually adjusts the steady-state level of AMPARs in the postsynaptic membrane (Figure 3). However, due to Syngap $1^{-1+}$ mutation, truncated SYGNAP1 fails to inhibit Ras activity, thereby facilitating conversion of inactive, GDP-bound Ras to an active, GTP-bound form and increasing the level of Ras activation. Ras is one of the important components of the signaling pathway underlying NMDA receptor mediated activation of ERK (Iida et al., 2001). Thus, increase in Ras activity elevates the level of phosphorylated ERK, which further facilitates the insertion of AMPARs to the postsynaptic membrane (Derkach et al., 2007). In this aspect, SYNGAP1 is a key molecule that facilitates a cross talk between CaMKII and Ras/MAPK signaling pathways that leads to AMPAR trafficking, thereby controlling the excitatory synaptic strength, particularly in developing neurons. However, SYNGAP1's control of excitatory synaptic strength during development is lacking in ID patients or in the Syngap $1^{-/+}$mice model.

Furthermore, increased level of Ras activation leads to activation of LIMKII, CDC42 and p-cofilin, which regulate actin 

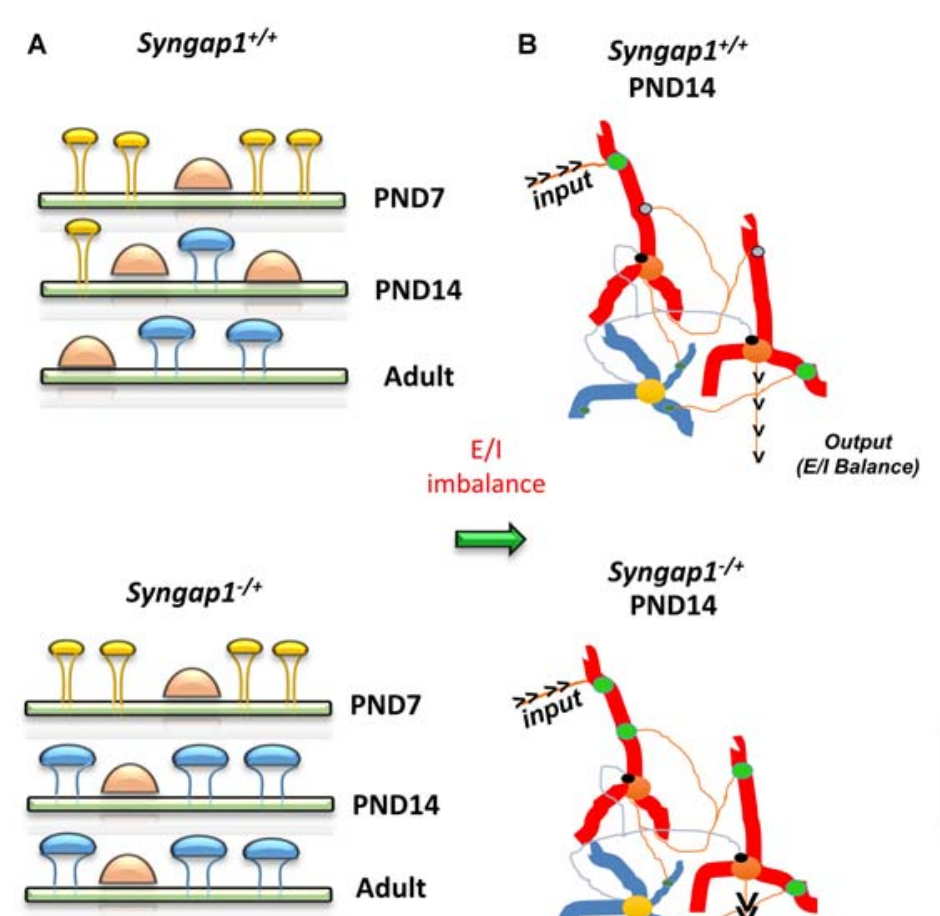

C

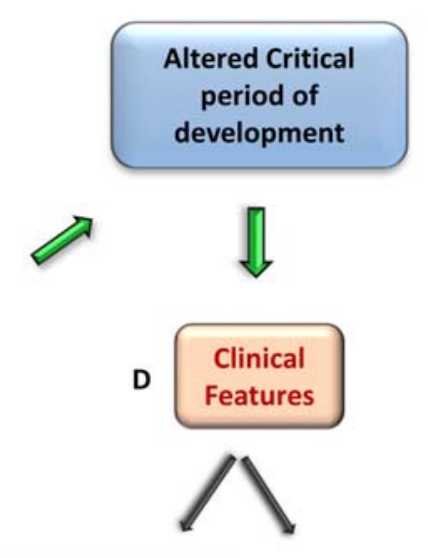

Learning \&

memory

deficits

\section{Epilepsy}

\section{Key: \\ $\bigcirc \quad$ Thin spine \\ Stubby spine \\ Excitatory \\ neuron}

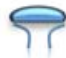

Mushroom spine

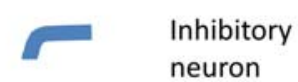

FIGURE 4 | Schematic model of the impact of Syngap1 haploinsufficiency on neuronal circuit function. This figure illustrates the impact of Syngap1 heterozygous mutation on dendritic spine morphology, neuronal connection organization, and behavioral phenotypes. Heterozygous mutations in Syngap1 lead to prematuration of dendritic spine morphology during early stages of development (A). This causes abnormal formation and elimination of spines that leads to altered spine density and excitatory neuronal connections during development in the cortex (Aceti et al., 2015). Further, the abnormal cortical excitatory neuronal connections lead to E/I imbalance during early stages of development, which persists, into adult stages in Syngap1 Hets (B). Consequently, these abnormalities bring about altered duration of critical period of development (C), which leads to cognitive and social dysfunction (D). PND, Post-natal Day. The gene products implicated in intellectual disability (ID) and/or autism spectrum disorder (ASD) are marked in Red color text. Some features are modified with permission based on Clement et al. (2012).

cytoskeleton (Figure 3). Actin is the major cytoskeletal element in dendritic spines, where it serves both as framework for the spine structure and as a scaffold for postsynaptic proteins (Dillon and Goda, 2005). Cofilin is best known as a regulator of actin whose assembly and disassembly depends upon the concentration of cofilin. In Syngap1 $1^{-/+}$mice, increased levels of p-Cofilin shift the equilibrium towards the more stable actin form, F-actin. This makes the dendritic spine more stable at 
an early stage of development. Thus, more stable form of actin combined with an increase in insertion of AMPAR into the postsynaptic membrane during development (PND14-16 in hippocampus in Hets) causes the dendritic spines to mature into mushroom shaped spines, which occurs earlier in Syngap1 $1^{-/+}$ than in WT animals (Figure 4).

This leads to elevated excitatory synaptic transmission causing Excitatory/Inhibitory (E/I) imbalance, particularly during the critical period of development. Due to the altered E/I balance, humans, as well as Syngap $1^{-/+}$mice, are prone to epileptic seizures. The altered E/I balance observed in Syngap $1^{-/+}$mice is representative of an altered form of synaptic homeostasis that degrades the ability of mature neurons to optimally balance excitation relative to inhibition. Indeed, truncation of SYNGAP1 occludes the ability of neurons to scale up synaptic strength in response to activity, suggesting that SYNGAP1 associated signaling is necessary for maintaining homeostatic synaptic plasticity (Wang et al., 2013). In fact, altered dendritic spine morphology and function during the critical period of development causes a coordinated acceleration of dendritic elongation, spine formation, and elimination (pruning) in cortical neurons, which may result in altered neuronal connectivity and abnormal closure of critical period plasticity (Figure 4). Interestingly, E/I imbalance in Syngap1 $1^{-/+}$ mutation leads to altered pruning of spines, which in turn causes abnormal connections (non-target) in neurons and negatively affects the organization of neuronal circuits (Aceti et al., 2015). The abnormal pruning of spines and connections between neurons could be a consequence of an altered duration of critical period observed in Syngap1 $1^{-/+}$mice. This would prevent the neuronal connections to be actively refined by the surrounding environment in which the individual exists.

There appear to be independent critical periods of development for different modalities, ranging from basic visual processing to language and social skills, which are observed to be affected in patients with SYNGAP1 heterozygous mutation. Syngap1 $1^{-/+}$mice displayed early closure of critical period of plasticity during development (Clement et al., 2013). The precise development of the timing of critical periods during cortical development is essential for the proper organization of synaptic connections and neuronal circuit formation. Thus, premature closure of plasticity window during development could contribute to altered refinement of cortical circuits that persist throughout the life of an animal and thus contributing to cognitive deficits in Syngap1 $1^{-/+}$mice. Thus, transient neurodevelopmental events induced by Syngap1 mutations could cause life-long disruptions to cognition and behavior that are difficult to treat in adulthood.

\section{ROLE OF ASTROCYTES IN ID AND ASD}

While neurons are considered as major players in brain function such as perception, social behavior and memory, astrocytes have been relegated to a far lesser supporting role. However, in recent years, emerging evidences suggest that signaling between astrocytes and neurons at the tripartite synapse plays an important role during the critical period of development
(Stevens, 2008; Clarke and Barres, 2013). Although astrocytes were considered to play a passive onlooker in the synapse, but studies show that, they are necessary for neuronal maturation, function, and development of neurons. During early stages of development, astrocytes and neurons are formed from neuronal precursor cells (Freeman, 2010). Three-dimensonal reconstructions of dye-filled astrocytes reveal that astrocytes extend thousands of intricate processes that are organized into large, non-overlapping anatomical domains. It has been estimated that a single astrocyte can associate with multiple neurons and over 100,000 synapses (Bushong et al., 2002; Halassa et al., 2007a,b). While astrocytes are incapable of generating action potentials, they do secrete a wide array of gliotransmitters and express many of the same channels, receptors and cell surface molecules similar to neurons (Haydon, 2000; Fields and StevensGraham, 2002; Fiacco and Mccarthy, 2006).

Neurons rely on astrocytes to instruct the formation and elimination of their synapses lead to the possibility that astrocytes work in parallel with and interacts with, the neuronal processes that control circuit formation. One of the first evidences that astrocytes contribute majorly in critical period of development came from a study by Muller and Best (1989) that injection of immature astrocytes into the adult visual cortex reopened the window of ocular dominance plasticity. Further, a study from purified rodent ganglion cells (RGCs) suggested that RGCs formed very few syanpses in the absesnce of astrocytes. However, when cultured in the presence of astrocytes, or in a medium that had been conditioned with any other soluble signals released by astrocytes, RGCs can form ten-fold more excitatory synapses and synaptic functionality was increased (Pfrieger and Barres, 1997; Ullian et al., 2001). Not only astrocytes regulate the development, maturation, and function of excitatory neurons, they are a requisite for the development of inhibitory synapses. Liu et al. (1996) showed that local contact between neurons and astrocytes significantly increased the amplitude and density of $\mathrm{GABA}_{\mathrm{A}}$ receptors in developing hippocampal neurons. In addition, astrocytes were shown to regulate chloride ion gradient in cultured spinal cord neurons and convert GABAergic neurons from excitatory to inhibitory (Li et al., 1998). These studies suggest that immature astrocytes are necessary for critical period of development and it is linked to maturation of astrocytes.

It is evident from the above mentioned studies that astrocytes play a major role in normal neuronal development and function, it would not be surprising that astrocytes contribute in some capacity to almost all pathological conditions of the nervous system (Lin and Koleske, 2010; Parpura et al., 2012). Consequently, astrocyte-dysregulated function has been linked with the progressive pathology of ischemic stroke, epilepsy and to a number of neurodegenerative disorders including amyotrophic lateral sclerosis, Huntington's disease, Parkinson's disease, Rett syndrome, FXS, and autism (Yamamuro et al., 2015). FXS is one of the most common form of ID and affects 1 in 4000 males and 1 in 6000 females. Fragile X mental retardation protein (FMRP) is reported to be expressed in Oligodendritic precursor cells but not mature oligodendrocytes (Wang et al., 2004). However, a study by Pacey and Doering (2007) reported expression of FMRP in astrocytes. Further, they showed that WT neurons grown 
on Fmr1 KO astrocytes exhibited significantly altered dendritic arbor morphologies, whereas Fmr1 KO neurons cultured with WT astrocytes, the alterations in dendritic morphologies and synaptic protein expression were prevented (Jacobs and Doering, 2010; Jacobs et al., 2010). These experiments were the first to suggest that astrocytes contribute to the normal development of dendritic spine morphology and function. Therefore, it is important to study the role of astrocytes in Syngap1-/+ mutations. However, there are no studies to date to suggest expression of Syngap1 in astrocytes or its role in ID due to Syngap $1^{-/+}$.

\section{CONCLUSION}

Basic research in ID and ASD using model organisms has been critical in advancing our understanding of many NDDs. Important insights into the neurophysiology of Syngap1 $1^{-/+}$ mutations, especially the regulation of dendritic spine formation and function, has been gained from the study of Syngap1-1+ mouse models. Although it is clear from these studies that SYNGAP1 is a negative regulator of AMPAR insertion in the postsynaptic membrane that regulates dendritic spine structure and function, certain questions still remain unanswered, such as which downstream proteins are regulated by affected by Syngap $1^{-/+}$mutations. The other major question is to find the precise window during development to address the symptoms observed in ID. In fact, repairing pathogenic Syngap $1^{-/+}$ mutation after the end of critical period of development failed to rescue neurophysiological and cognitive functions. Therefore, it is important to find the right period of development in order to rescue the cognitive deficits observed in Syngap $1^{-/+}$

\section{REFERENCES}

Aceti, M., Creson, T. K., Vaissiere, T., Rojas, C., Huang, W. C., Wang, Y. X., et al. (2015). Syngap1 haploinsufficiency damages a postnatal critical period of pyramidal cell structural maturation linked to cortical circuit assembly. Biol. Psychiatry 77, 805-815. doi: 10.1016/j.biopsych.2014.08.001

Araki, Y., Zeng, M., Zhang, M., and Huganir, R. L. (2015). Rapid dispersion of SynGAP from synaptic spines triggers AMPA receptor insertion and spine enlargement during LTP. Neuron 85, 173-189. doi: 10.1016/j.neuron.2014. 12.023

Auerbach, B. D., Osterweil, E. K., and Bear, M. F. (2011). Mutations causing syndromic autism define an axis of synaptic pathophysiology. Nature 480, 63-68. doi: 10.1038/nature10658

Azevedo, F. A., Carvalho, L. R., Grinberg, L. T., Farfel, J. M., Ferretti, R. E., Leite, R. E., et al. (2009). Equal numbers of neuronal and nonneuronal cells make the human brain an isometrically scaled-up primate brain. J. Comp. Neurol. 513, 532-541. doi: 10.1002/cne.21974

Bailey, K. R., Rustay, N. R., and Crawley, J. N. (2006). Behavioral phenotyping of transgenic and knockout mice: practical concerns and potential pitfalls. ILAR J. 47, 124-131. doi: 10.1093/ilar.47.2.124

Bear, M. F., Huber, K. M., and Warren, S. T. (2004). The mGluR theory of fragile X mental retardation. Trends Neurosci. 27, 370-377. doi: 10.1016/j.tins.2004. 04.009

Belsham, B. (2001). Glutamate and its role in psychiatric illness. Hum. Psychopharmacol. 16, 139-146. doi: 10.1002/hup.279.abs

Berryer, M. H., Hamdan, F. F., Klitten, L. L., Moller, R. S., Carmant, L., Schwartzentruber, J., et al. (2013). Mutations in SYNGAP1 cause intellectual disability, autism and a specific form of epilepsy by inducing mutation. One of the means of finding therapeutic targets is to find a protein which has been implicated in another ID and ASD that produces similar or opposite cellular and behavioral phenotypes as that of Syngap1 $1^{-/+}$mutants. The opposing effects of these mutations may balance one another at synaptic and behavioral function (Auerbach et al., 2011). Understanding the effect of complementary pathways to rescue a gene of interest, for example Syngap1 $1^{-/+}$mutation, would allow better therapeutic designs to alleviate ID symptoms (earlier the better). It is important to understand where an ID and ASD patient lies on the spectrum of synaptic and behavioral dysfunction to choose an appropriate therapy. Thus, continued study of various disorders that exhibit ID and ASD phenotypes may lead to better therapeutic targets.

\section{AUTHOR CONTRIBUTIONS}

All authors listed, have made substantial, direct and intellectual contribution to the work, and approved it for publication.

\section{ACKNOWLEDGMENTS}

NJ and JPC would like to thank Ms. Varsha Ramakrishna and Ms. Vrushali Rao for their assistance in preparing the figures. NJ and JPC would like to thank Department of Science and Technology (DST)-Science and Engineering Board (SERB) for the support. JPC would like to thank Dr. Ravi Manjithaya for critical comments and suggestions. NJ and JPC would like to thank Narayana Nethrayala Foundation and Jawaharlal Nehru Centre for Advanced Scientific Research (JNCASR) respectively for their constant support.

haploinsufficiency. Hum. Mutat. 34, 385-394. doi: 10.1002/humu. 22248

Bhakar, A. L., Dolen, G., and Bear, M. F. (2012). The pathophysiology of fragile $\mathrm{X}$ (and what it teaches us about synapses). Annu. Rev. Neurosci. 35, 417-443. doi: 10.1146/annurev-neuro-060909-153138

Bienvenu, T., and Chelly, J. (2006). Molecular genetics of Rett syndrome: when DNA methylation goes unrecognized. Nat. Rev. Genet. 7, 415-426. doi: 10. $1038 / \operatorname{nrg} 1878$

Boda, B., Mas, C., and Muller, D. (2002). Activity-dependent regulation of genes implicated in X-linked non-specific mental retardation. Neuroscience 114, 13-17. doi: 10.1016/s0306-4522(02)00218-X

Branchi, I., Bichler, Z., Berger-Sweeney, J., and Ricceri, L. (2003). Animal models of mental retardation: from gene to cognitive function. Neurosci. Biobehav. Rev. 27, 141-153. doi: 10.1016/s0149-7634(03)00016-2

Bushong, E. A., Martone, M. E., Jones, Y. Z., and Ellisman, M. H. (2002). Protoplasmic astrocytes in CA1 stratum radiatum occupy separate anatomical domains. J. Neurosci. 22, 183-192. doi: 0270-6474/01/220183-10

Carlisle, H. J., and Kennedy, M. B. (2005). Spine architecture and synaptic plasticity. Trends Neurosci. 28, 182-187. doi: 10.1016/j.tins.2005.01.008

Carlisle, H. J., Manzerra, P., Marcora, E., and Kennedy, M. B. (2008). SynGAP regulates steady-state and activity-dependent phosphorylation of cofilin. J. Neurosci. 28, 13673-13683. doi: 10.1523/jneurosci.4695-08.2008

Chechlacz, M., and Gleeson, J. G. (2003). Is mental retardation a defect of synapse structure and function?. Pediatr. Neurol. 29, 11-17. doi: 10.1016/s08878994(03)00152-8

Chelly, J., Khelfaoui, M., Francis, F., Chérif, B., and Bienvenu, T. (2006). Genetics and pathophysiology of mental retardation. Eur. J. Hum. Genet. 14, 701-713. doi: 10.1038/sj.ejhg.5201595 
Chen, H. J., Rojas-Soto, M., Oguni, A., and Kennedy, M. B. (1998). A synaptic RasGTPase activating protein (p135 SynGAP) inhibited by CaM kinase II. Neuron 20, 895-904. doi: 10.1016/s0896-6273(00)80471-7

Clarke, L. E., and Barres, B. A. (2013). Emerging roles of astrocytes in neural circuit development. Nat. Rev. Neurosci. 14, 311-321. doi: 10.1038/nrn3484

Clement, J. P., Aceti, M., Creson, T. K., Ozkan, E. D., Shi, Y., Reish, N. J., et al. (2012). Pathogenic SYNGAP1 mutations impair cognitive development by disrupting maturation of dendritic spine synapses. Cell 151, 709-723. doi: 10. 1016/j.cell.2012.08.045

Clement, J. P., Ozkan, E. D., Aceti, M., Miller, C. A., and Rumbaugh, G. (2013). SYNGAP1 links the maturation rate of excitatory synapses to the duration of critical-period synaptic plasticity. J. Neurosci. 33, 10447-10452. doi: 10. 1523/jneurosci.0765-13.2013

Crair, M. C., and Malenka, R. C. (1995). A critical period for long-term potentiation at thalamocortical synapses. Nature 375, 325-328. doi: 10 . $1038 / 375325 \mathrm{a} 0$

Crawley, J. N. (2008). Behavioral phenotyping strategies for mutant mice. Neuron 57, 809-818. doi: 10.1016/j.neuron.2008.03.001

Crow, J. F. (2000a). The origins, patterns and implications of human spontaneous mutation. Nat. Rev. Genet. 1, 40-47. doi: 10.1038/35049558

Crow, J. F. (2000b). Two centuries of genetics: a view from halftime. Annu. Rev. Genomics. Hum. Genet. 1, 21-40. doi: 10.1146/annurev.genom.1.1.21

Crow, J. F. (2006). Age and sex effects on human mutation rates: an old problem with new complexities. J. Radiat. Res. 47 (Suppl. B), B75-B82. doi: 10.1269/jrr. 47.b75

Daw, M. I., Scott, H. L., and Isaac, J. T. (2007). Developmental synaptic plasticity at the thalamocortical input to barrel cortex: mechanisms and roles. Mol. Cell. Neurosci. 34, 493-502. doi: 10.1016/j.mcn.2007.01.001

Derkach, V. A., Oh, M. C., Guire, E. S., and Soderling, T. R. (2007). Regulatory mechanisms of AMPA receptors in synaptic plasticity. Nat. Rev. Neurosci. 8, 101-113. doi: 10.1038/nrn2055

Dillon, C., and Goda, Y. (2005). The actin cytoskeleton: integrating form and function at the synapse. Annu. Rev. Neurosci. 28, 25-55. doi: 10.1146/annurev. neuro.28.061604.135757

Fan, X., Jin, W. Y., and Wang, Y. T. (2014). The NMDA receptor complex: a multifunctional machine at the glutamatergic synapse. Front. Cell. Neurosci. 8:160. doi: $10.3389 /$ fncel.2014.00160

Feldman, D. E., and Knudsen, E. I. (1998). Experience-dependent plasticity and the maturation of glutamatergic synapses. Neuron 20, 1067-1071. doi: 10 . 1016/s0896-6273(00)80488-2

Feldman, D. E., Nicoll, R. A., Malenka, R. C., and Isaac, J. T. (1998). Long-term depression at thalamocortical synapses in developing rat somatosensory cortex. Neuron 21, 347-357. doi: 10.1016/s0896-6273(00)80544-9

Fiacco, T. A., and Mccarthy, K. D. (2006). Astrocyte calcium elevations: properties, propagation and effects on brain signaling. Glia 54, 676-690. doi: 10.1002/glia. 20396

Fields, R. D., and Stevens-Graham, B. (2002). New insights into neuron-glia communication. Science 298, 556-562. doi: 10.1126/science.298.5593.556

Freeman, M. R. (2010). Specification and morphogenesis of astrocytes. Science 330, 774-778. doi: 10.1126/science.1190928

Funk, A. J., Rumbaugh, G., Harotunian, V., Mccullumsmith, R. E., and Meador-Woodruff, J. H. (2009). Decreased expression of NMDA receptor-associated proteins in frontal cortex of elderly patients with schizophrenia. Neuroreport 20, 1019-1022. doi: 10.1097/wnr.0b013e3283 2d30d9

Gauthier, J., Siddiqui, T. J., Huashan, P., Yokomaku, D., Hamdan, F. F., Champagne, N., et al. (2011). Truncating mutations in NRXN2 and NRXN1 in autism spectrum disorders and schizophrenia. Hum. Genet. 130, 563-573. doi: 10.1007/s00439-011-0975-Z

Gécz, J., Shoubridge, C., and Corbett, M. (2009). The genetic landscape of intellectual disability arising from chromosome X. Trends Genet. 25, 308-316. doi: 10.1016/j.tig.2009.05.002

Goncalves, J. T., Anstey, J. E., Golshani, P., and Portera-Cailliau, C. (2013). Circuit level defects in the developing neocortex of Fragile X mice. Nat. Neurosci. 16, 903-909. doi: 10.1038/nn.3415

Grabowski, P. (2011). Alternative splicing takes shape during neuronal development. Curr. Opin. Genet. Dev. 21, 388-394. doi: 10.1016/j.gde.2011. 03.005
Grant, S. G., and O'dell, T. J. (2001). Multiprotein complex signaling and the plasticity problem. Curr. Opin. Neurobiol. 11, 363-368. doi: 10.1016/s09594388(00)00220-8

Guo, X., Hamilton, P. J., Reish, N. J., Sweatt, J. D., Miller, C. A., and Rumbaugh, G. (2009). Reduced expression of the NMDA receptor-interacting protein SynGAP causes behavioral abnormalities that model symptoms of Schizophrenia. Neuropsychopharmacology 34, 1659-1672. doi: 10.1038/npp. 2008.223

Halassa, M. M., Fellin, T., and Haydon, P. G. (2007a). The tripartite synapse: roles for gliotransmission in health and disease. Trends. Mol. Med. 13, 54-63. doi: 10 1016/j.molmed.2006.12.005

Halassa, M. M., Fellin, T., Takano, H., Dong, J. H., and Haydon, P. G. (2007b). Synaptic islands defined by the territory of a single astrocyte. J. Neurosci. 27, 6473-6477. doi: 10.1523/jneurosci.1419-07.2007

Hamdan, F. F., Daoud, H., Piton, A., Gauthier, J., Dobrzeniecka, S., Krebs, M. O., et al. (2011a). De novo SYNGAP1 mutations in nonsyndromic intellectual disability and autism. Biol. Psychiatry 69, 898-901. doi: 10.1016/j.biopsych. 2010.11.015

Hamdan, F. F., Gauthier, J., Araki, Y., Lin, D. T., Yoshizawa, Y., Higashi, K., et al. (2011b). Excess of de novo deleterious mutations in genes associated with glutamatergic systems in nonsyndromic intellectual disability. Am. J. Hum. Genet. 88, 306-316. doi: 10.1016/j.ajhg.2011.02.001

Hamdan, F. F., Gauthier, J., Spiegelman, D., Noreau, A., Yang, Y., Pellerin, S., et al. (2009). Mutations in SYNGAP1 in autosomal nonsyndromic mental retardation. N. Engl. J. Med. 360, 599-605. doi: 10.1056/nejmx0 90052

Hamdan, F. F., Srour, M., Capo-Chichi, J. M., Daoud, H., Nassif, C., Patry, L., et al. (2014). De novo mutations in moderate or severe intellectual disability. PLoS Genet. 10:e1004772. doi: 10.1371/journal.pgen. 1004772

Haydon, P. G. (2000). Neuroglial networks: neurons and glia talk to each other. Curr. Biol. 10, R712-R714. doi: 10.1016/s0960-9822(00)00708-9

Hensch, T. K. (2005). Critical period plasticity in local cortical circuits. Nat. Rev. Neurosci. 6, 877-888. doi: 10.1038/nrn1787

Huang, K. (2009). SYNGAP: bridging the gap between genetic factors and autosomal non-syndromic mental retardation. Clin. Genet. 76, 149-151. doi: 10.1111/j.1399-0004.2009.01247_3.x

Husi, H., Ward, M. A., Choudhary, J. S., Blackstock, W. P., and Grant, S. G. (2000). Proteomic analysis of NMDA receptor-adhesion protein signaling complexes. Nat. Neurosci. 3, 661-669. doi: 10.1038/76615

Iida, N., Namikawa, K., Kiyama, H., Ueno, H., Nakamura, S., and Hattori, S. (2001). Requirement of Ras for the activation of mitogen-activated protein kinase by calcium influx, cAMP and neurotrophin in hippocampal neurons. J. Neurosci. 21, 6459-6466. doi: 0270-6474/01/216459-08

Jacobs, S., and Doering, L. C. (2010). Astrocytes prevent abnormal neuronal development in the fragile $\mathrm{x}$ mouse. J. Neurosci. 30, 4508-4514. doi: 10 . 1523/jneurosci.5027-09.2010

Jacobs, S., Nathwani, M., and Doering, L. C. (2010). Fragile X astrocytes induce developmental delays in dendrite maturation and synaptic protein expression. BMC Neurosci. 11:132. doi: 10.1186/1471-2202-11-132

Kennedy, M. B. (1997). The postsynaptic density at glutamatergic synapses. Trends Neurosci. 20, 264-268.

Kennedy, M. B., Beale, H. C., Carlisle, H. J., and Washburn, L. R. (2005). Integration of biochemical signalling in spines. Nat. Rev. Neurosci. 6, 423-434. doi: $10.1038 /$ nrn 1685

Kerchner, G. A., and Nicoll, R. A. (2008). Silent synapses and the emergence of a postsynaptic mechanism for LTP. Nat. Rev. Neurosci. 9, 813-825. doi: 10. 1038/nrn2501

Kim, J. H., Lee, H. K., Takamiya, K., and Huganir, R. L. (2003). The role of synaptic GTPase-activating protein in neuronal development and synaptic plasticity. J. Neurosci. 23, 1119-1124.

Kim, J. H., Liao, D., Lau, L. F., and Huganir, R. L. (1998). SynGAP: a synaptic RasGAP that associates with the PSD-95/SAP90 protein family. Neuron 20 , 683-691. doi: 10.1016/s0896-6273(00)81008-9

Kim, J. S., Kornhuber, H. H., Schmid-Burgk, W., and Holzmuller, B. (1980). Low cerebrospinal fluid glutamate in schizophrenic patients and a new hypothesis on schizophrenia. Neurosci. Lett. 20, 379-382. doi: 10.1016/03043940(80)90178-0 
Knuesel, I., Elliott, A., Chen, H. J., Mansuy, I. M., and Kennedy, M. B. (2005). A role for synGAP in regulating neuronal apoptosis. Eur. J. Neurosci. 21, 611-621. doi: 10.1111/j.1460-9568.2005.03908.x

Komiyama, N. H., Watabe, A. M., Carlisle, H. J., Porter, K., Charlesworth, P., Monti, J., et al. (2002). SynGAP regulates ERK/MAPK signaling, synaptic plasticity and learning in the complex with postsynaptic density 95 and NMDA receptor. J. Neurosci. 22, 9721-9732. doi: 0270-6474/02/229721-12

Krapivinsky, G., Medina, I., Krapivinsky, L., Gapon, S., and Clapham, D. E. (2004). SynGAP-MUPP1-CaMKII synaptic complexes regulate p38 MAP kinase activity and NMDA receptor-dependent synaptic AMPA receptor potentiation. Neuron 43, 563-574. doi: 10.1016/j.neuron.2004.08.003

Krepischi, A. C., Rosenberg, C., Costa, S. S., Crolla, J. A., Huang, S., and Vianna-Morgante, A. M. (2010). A novel de novo microdeletion spanning the SYNGAP1 gene on the short arm of chromosome 6 associated with mental retardation. Am. J. Med. Genet. A 152A, 2376-2378. doi: 10.1002/ajmg.a. 33554

Kroon, T., Sierksma, M. C., and Meredith, R. M. (2013). Investigating mechanisms underlying neurodevelopmental phenotypes of autistic and intellectual disability disorders: a perspective. Front. Syst. Neurosci. 7:75. doi: 10.3389/fnsys. 2013.00075

Lai, K. O., and Ip, N. Y. (2013). Structural plasticity of dendritic spines: the underlying mechanisms and its dysregulation in brain disorders. Biochim. Biophys. Acta 1832, 2257-2263. doi: 10.1016/j.bbadis.2013.08.012

Lau, C. G., and Zukin, R. S. (2007). NMDA receptor trafficking in synaptic plasticity and neuropsychiatric disorders. Nat. Rev. Neurosci. 8, 413-426. doi: $10.1038 / \mathrm{nrn} 2171$

Lemmon, M. A., and Ferguson, K. M. (2000). Signal-dependent membrane targeting by pleckstrin homology (PH) domains. Biochem. J. 350, 1-18. doi: 10 . 1042/bj3500001

Li, Q., Lee, J. A., and Black, D. L. (2007). Neuronal regulation of alternative premRNA splicing. Nat. Rev. Neurosci. 8, 819-831. doi: 10.1038/nrn2237

Li, Y. X., Schaffner, A. E., Walton, M. K., and Barker, J. L. (1998). Astrocytes regulate developmental changes in the chloride ion gradient of embryonic rat ventral spinal cord neurons in culture. J. Physiol. 509, 847-858. doi: 10.1111/j. 1469-7793.1998.847bm.x

Lin, Y. C., and Koleske, A. J. (2010). Mechanisms of synapse and dendrite maintenance and their disruption in psychiatric and neurodegenerative disorders. Annu. Rev. Neurosci. 33, 349-378. doi: 10.1146/annurev-neuro060909-153204

Lipscombe, D. (2005). Neuronal proteins custom designed by alternative splicing. Curr. Opin. Neurobiol. 15, 358-363. doi: 10.1016/j.conb.2005.04.002

Liu, Q. Y., Schaffner, A. E., Li, Y. X., Dunlap, V., and Barker, J. L. (1996). Upregulation of GABAA current by astrocytes in cultured embryonic rat hippocampal neurons. J. Neurosci. 16, 2912-2923.

McKinney, R. A. (2005). Physiological roles of spine motility: development, plasticity and disorders. Biochem. Soc. Trans. 33, 1299-1302. doi: 10. 1042/bst0331299

McMahon, A. C., Barnett, M. W., O’leary, T. S., Stoney, P. N., Collins, M. O., Papadia, S., et al. (2012). SynGAP isoforms exert opposing effects on synaptic strength. Nat. Commun. 3:900. doi: 10.1038/ncomms1900

Melom, J. E., and Littleton, J. T. (2011). Synapse development in health and disease. Curr. Opin. Genet. Dev. 21, 256-261. doi: 10.1016/j.gde.2011.01.002

Meredith, R. M., Dawitz, J., and Kramvis, I. (2012). Sensitive time-windows for susceptibility in neurodevelopmental disorders. Trends Neurosci. 35, 335-344. doi: 10.1016/j.tins.2012.03.005

Muhia, M., Yee, B. K., Feldon, J., Markopoulos, F., and Knuesel, I. (2010). Disruption of hippocampus-regulated behavioural and cognitive processes by heterozygous constitutive deletion of SynGAP. Eur. J. Neurosci. 31, 529-543. doi: 10.1111/j.1460-9568.2010.07079.x

Muller, C. M., and Best, J. (1989). Ocular dominance plasticity in adult cat visual cortex after transplantation of cultured astrocytes. Nature 342, 427-430. doi: 10. 1038/342427a0

Niethammer, M., Kim, E., and Sheng, M. (1996). Interaction between the C terminus of NMDA receptor subunits and multiple members of the PSD-95 family of membrane-associated guanylate kinases. J. Neurosci. 16, 2157-2163.

Noguchi, J., Nagaoka, A., Watanabe, S., Ellis-Davies, G. C., Kitamura, K., Kano, M., et al. (2011). In vivo two-photon uncaging of glutamate revealing the structure-function relationships of dendritic spines in the neocortex of adult mice. J. Physiol. Lond. 589, 2447-2457. doi: 10.1113/jphysiol.2011. 207100

Ogden, K. K., Ozkan, E. D., and Rumbaugh, G. (2015). Prioritizing the development of mouse models for childhood brain disorders. Neuropharmacology. 100, 2-16. doi: 10.1016/j.neuropharm.2015.07.029

Ozkan, E. D., Creson, T. K., Kramar, E. A., Rojas, C., Seese, R. R., Babyan, A. H., et al. (2014). Reduced cognition in Syngap1 mutants is caused by isolated damage within developing forebrain excitatory neurons. Neuron 82, 1317-1333. doi: 10.1016/j.neuron.2014.05.015

Pacey, L. K., and Doering, L. C. (2007). Developmental expression of FMRP in the astrocyte lineage: implications for fragile X syndrome. Glia 55, 1601-1609. doi: 10.1002/glia.20573

Parpura, V., Heneka, M. T., Montana, V., Oliet, S. H., Schousboe, A., Haydon, P. G., et al. (2012). Glial cells in (patho)physiology. J. Neurochem. 121, 4-27. doi: 10.1111/j.1471-4159.2012.07664.x

Patterson, M., and Yasuda, R. (2011). Signalling pathways underlying structural plasticity of dendritic spines. Br. J. Pharmacol. 163, 1626-1638. doi: 10.1111/j. 1476-5381.2011.01328.x

Pavlowsky, A., Chelly, J., and Billuart, P. (2012). Emerging major synaptic signaling pathways involved in intellectual disability. Mol. Psychiatry 17, 682-693. doi: 10.1038/mp.2011.139

Peca, J., Feliciano, C., Ting, J. T., Wang, W., Wells, M. F., Venkatraman, T. N., et al. (2011). Shank3 mutant mice display autistic-like behaviours and striatal dysfunction. Nature 472, 437-442. doi: 10.1038/nature09965

Pena, V., Hothorn, M., Eberth, A., Kaschau, N., Parret, A., Gremer, L., et al. (2008). The C2 domain of SynGAP is essential for stimulation of the Rap GTPase reaction. EMBO Rep. 9, 350-355. doi: 10.1038/embor.2008.20

Penzes, P., Cahill, M. E., Jones, K. A., Vanleeuwen, J. E., and Woolfrey, K. M. (2011). Dendritic spine pathology in neuropsychiatric disorders. Nat. Neurosci. 14, 285-293. doi: 10.1038/nn.2741

Pèrez-Otaño, I., and Ehlers, M. D. (2004). Learning from NMDA receptor trafficking: clues to the development and maturation of glutamatergic synapses. Neurosignals 13, 175-189. doi: 10.1159/000077524

Pfrieger, F. W., and Barres, B. A. (1997). Synaptic efficacy enhanced by glial cells in vitro. Science $277,1684-1687$. doi: 10.1126/science.277.5332.1684

Porter, K., Komiyama, N. H., Vitalis, T., Kind, P. C., and Grant, S. G. N. (2005). Differential expression of two NMDA receptor interacting proteins, PSD-95 and SynGAP during mouse development. Eur. J. Neurosci. 21, 351-362. doi: 10 $1111 / \mathrm{j} .1460-9568.2005 .03874 . \mathrm{x}$

Raj, B., and Blencowe, B. J. (2015). Alternative splicing in the mammalian nervous system: recent insights into mechanisms and functional roles. Neuron 87, 14-27. doi: 10.1016/j.neuron.2015.05.004

Ramocki, M. B., and Zoghbi, H. Y. (2008). Failure of neuronal homeostasis results in common neuropsychiatric phenotypes. Nature 455, 912-918. doi: 10. 1038/nature 07457

Ropers, H. H., and Hamel, B. C. (2005). X-linked mental retardation. Nat. Rev. Genet. 6, 46-57. doi: 10.1038/nrg1501

Rumbaugh, G., Adams, J. P., Kim, J. H., and Huganir, R. L. (2006). SynGAP regulates synaptic strength and mitogen-activated protein kinases in cultured neurons. Proc. Natl. Acad. Sci. USA 103, 4344-4351. doi: 10.1073/pnas. 0600084103

Spooren, W., Lindemann, L., Ghosh, A., and Santarelli, L. (2012). Synapse dysfunction in autism: a molecular medicine approach to drug discovery in neurodevelopmental disorders. Trends Pharmacol. Sci. 33, 669-684. doi: 10. 1016/j.tips.2012.09.004

State, M. W., and Levitt, P. (2011). The conundrums of understanding genetic risks for autism spectrum disorders. Nat. Neurosci. 14, 1499-1506. doi: 10.1038/nn. 2924

State, M. W., and Sestan, N. (2012). The emerging biology of Autism Spectrum Disorders. Science 337, 1301-1303. doi: 10.1126/science. 1224989

Stevens, B. (2008). Neuron-astrocyte signaling in the development and plasticity of neural circuits. Neurosignals 16, 278-288. doi: 10.1159/000123038

Südhof, T. C. (2008). Neuroligins and neurexins link synaptic function to cognitive disease. Nature 455, 903-911. doi: 10.1038/nature07456

Ullian, E. M., Sapperstein, S. K., Christopherson, K. S., and Barres, B. A. (2001). Control of synapse number by glia. Science 291, 657-661. doi: 10.1126/science. 291.5504 .657 
van Bokhoven, H. (2011). Genetic and epigenetic networks in intellectual disabilities. Annu. Rev. Genet. 45, 81-104. doi: 10.1146/annurev-genet-110410132512

van der Staay, F. J., Arndt, S. S., and Nordquist, R. E. (2009). Evaluation of animal models of neurobehavioral disorders. Behav. Brain Funct. 5:11. doi: 10. 1186/1744-9081-5-11

van Spronsen, M., and Hoogenraad, C. C. (2010). Synapse pathology in psychiatric and neurologic disease. Curr. Neurol. Neurosci. Rep. 10, 207-214. doi: 10. 1007/s11910-010-0104-8

Vazquez, L. E., Chen, H. J., Sokolova, I., Knuesel, I., and Kennedy, M. B. (2004). SynGAP regulates spine formation. J. Neurosci. 24, 8862-8872. doi: 10. 1523/jneurosci.3213-04.2004

Volianskis, A., France, G., Jensen, M. S., Bortolotto, Z. A., Jane, D. E., and Collingridge, G. L. (2015). Long-term potentiation and the role of N-methyl-daspartate receptors. Brain Res. 1621, 5-16. doi: 10.1016/j.brainres.2015.01.016

Volk, L., Chiu, S. L., Sharma, K., and Huganir, R. L. (2015). Glutamate synapses in human cognitive disorders. Annu. Rev. Neurosci. 38, 127-149. doi: 10. 1146/annurev-neuro-071714-033821

Volk, L. J., Pfeiffer, B. E., Gibson, J. R., and Huber, K. M. (2007). Multiple GqCoupled receptors converge on a common protein synthesis-dependent longterm depression that is affected in fragile $\mathrm{X}$ syndrome mental retardation. J. Neurosci. 27, 11624-11634. doi: 10.1523/jneurosci.2266-07.2007

Walkup, W. G. T., Washburn, L., Sweredoski, M. J., Carlisle, H. J., Graham, R. L., Hess, S., et al. (2015). Phosphorylation of synaptic GTPase-activating protein (synGAP) by $\mathrm{Ca} 2+/$ calmodulin-dependent protein kinase II (CaMKII) and cyclin-dependent kinase 5 (CDK5) alters the ratio of its GAP activity toward Ras and Rap GTPases. J. Biol. Chem. 290, 4908-4927. doi: 10.1074/jbc.m114. 614420

Wang, C. C., Held, R. G., and Hall, B. J. (2013). SynGAP regulates protein synthesis and homeostatic synaptic plasticity in developing cortical networks. PLoS One 8:e83941. doi: 10.1371/journal.pone.0083941

Wang, H., Ku, L., Osterhout, D. J., Li, W., Ahmadian, A., Liang, Z., et al. (2004). Developmentally-programmed FMRP expression in oligodendrocytes: a potential role of FMRP in regulating translation in oligodendroglia progenitors. Hum. Mol. Genet. 13, 79-89. doi: 10.1093/hmg/ddh009
Writzl, K., and Knegt, A. C. (2013). 6p21.3 microdeletion involving the SYNGAP1 gene in a patient with intellectual disability, seizures and severe speech impairment. Am. J. Med. Genet. A. 161A, 1682-1685. doi: 10.1002/ajmg.a. 35930

$\mathrm{Xu}$, W. (2011). PSD-95-like membrane associated guanylate kinases (PSDMAGUKs) and synaptic plasticity. Curr. Opin. Neurobiol. 21, 306-312. doi: 10. 1016/j.conb.2011.03.001

Yamamuro, K., Kimoto, S., Rosen, K. M., Kishimoto, T., and Makinodan, M. (2015). Potential primary roles of glial cells in the mechanisms of psychiatric disorders. Front. Cell. Neurosci. 9:154. doi: 10.3389/fncel.2015.00154

Yang, Y., Tao-Cheng, J. H., Bayer, K. U., Reese, T. S., and Dosemeci, A. (2013). Camkii-mediated phosphorylation regulates distributions of Syngapalpha1 and -alpha2 at the postsynaptic density. PLoS One 8:e71795. doi: 10. 1371/journal.pone.0071795

Yashiro, K., and Philpot, B. D. (2008). Regulation of NMDA receptor subunit expression and its implications for LTD, LTP and metaplasticity. Neuropharmacology 55, 1081-1094. doi: 10.1016/j.neuropharm.2008.07.046

Zoghbi, H. Y., and Bear, M. F. (2012). Synaptic dysfunction in neurodevelopmental disorders associated with autism and intellectual disabilities. Cold Spring Harb. Perspect. Biol. 4:a009886. doi: 10.1101/cshperspect.a009886

Zollino, M., Gurrieri, F., Orteschi, D., Marangi, G., Leuzzi, V., and Neri, G. (2011). Integrated analysis of clinical signs and literature data for the diagnosis and therapy of a previously undescribed 6p21.3 deletion syndrome. Eur. J. Hum. Genet. 19, 239-242. doi: 10.1038/ejhg.2010.172

Conflict of Interest Statement: The authors declare that the research was conducted in the absence of any commercial or financial relationships that could be construed as a potential conflict of interest.

Copyright (C) 2016 Jeyabalan and Clement. This is an open-access article distributed under the terms of the Creative Commons Attribution License (CC BY). The use, distribution and reproduction in other forums is permitted, provided the original author(s) or licensor are credited and that the original publication in this journal is cited, in accordance with accepted academic practice. No use, distribution or reproduction is permitted which does not comply with these terms. 